\title{
Unobservable shocks as carriers of contagion
}

\author{
Mardi Dungey ${ }^{a}$, George Milunovich $^{b}$, Susan Thorp ${ }^{c, *}$ \\ ${ }^{a}$ School of Economics and Finance, University of Tasmania; CFAP, University of \\ Cambridge \\ ${ }^{b}$ Department of Economics, Macquarie University \\ ${ }^{c}$ School of Finance and Economics, University of Technology, Sydney
}

This version: 2 November 2009

\begin{abstract}
We propose an identified structural GARCH model to disentangle the dynamics of financial market crises. We distinguish between the hypersensitivity of a domestic market in crisis to news from foreign non-crisis markets, and the contagion imported to a tranquil domestic market from foreign crises. The model also enables us to connect unobserved structural shocks with their source markets using variance decompositions and to compare the size and dynamics of impulses during crises periods with tranquil period impulses. To illustrate, we apply the method to data from the 1997-1998 Asian financial crisis which consists of a complicated set of interacting crises. We find significant hypersensitivity and contagion between these markets but also show that links may strengthen or weaken. Impulse response functions for an equally weighted equity portfolio show the increasing dominance of Korean and Hong Kong shocks during the crises and covariance responses demonstrate multiple layers of contagion effects.
\end{abstract}

JEL classification: G01; C51

Keywords: Contagion; Structural GARCH

\footnotetext{
*Corresponding author. Tel.:+61 29514 7784; fax: +61 294157711.

Email addresses: mardi.dungey@utas.edu.au (M.Dungey), gmilunov@efs.mq.edu.au (G. Milunovich), susan.thorp@uts.edu.au (S. Thorp).
} 


\section{Introduction}

An important unanswered question concerning financial crises is whether it is possible to separately identify and measure shocks emerging from a particular source market. As well as disrupting markets in the country where trouble begins, financial crises may spread turmoil into foreign markets in a phenomenon often labelled 'contagion'. ${ }^{1}$ Here we develop a method for separating these increased crisis-period linkages into two categories. The first category is hypersensitivity to information from elsewhere during a local crisis, in other words, where turmoil at home changes the way a domestic market reacts to news from foreign markets. The second category is changes to the impact of news from a troubled foreign market on (potentially non-crisis) domestic markets - we restrict the label 'contagion' to this second effect. These categories can be separately measured whenever domestic and foreign crises are not totally coincident. ${ }^{2}$

This distinction is not an unnecessary abstraction since each category supports different crisis management and prevention policies. While the domestic policy makers of a country in crisis are likely to be interested in preventing increasing hypersensitivity, that is, preventing their own troubled market from over-reacting to external news, they have little incentive to prevent their crisis spreading to foreign markets. On the other hand, such a crisis may generate externalities to other countries in the form of contagion so that governments and market participants in non-crisis countries may want to protect their markets from foreign-sourced trouble, if possible. The existence of these externalities is consistent with the agenda for coordinated global reforms in regulation, financial infrastructure and instrument design following major incidents.

Here we model contemporaneous linkages between financial markets during normal times, as well as changes during crisis periods. In order to capture the well-known clustering of financial returns, we base our analysis in a multivariate GARCH model of asset

\footnotetext{
${ }^{1}$ Consistent with recent literature, we here refer to 'pure' contagion in the terminology of Dornbusch et al. (2000) and Kaminsky and Reinhart (2002), as distinct from crisis-driven changes in fundamental linkages.

${ }^{2}$ Theoretical models of contagion propose mechanisms such as information asymmetry and portfolio rebalancing (Kodres and Pritsker, 2002; Yuan, 2005), institutional and regulatory linkages, and relationship complexity (Allen and Gale, 2000; Brusco and Catiglionesi, 2007; Pavlova and Rigobon, 2007). Recent network theory tallies particularly well with the empirical framework developed here, see Allen and Babus, (2008).
} 
market interaction. However we do not simply work with the standard spillovers from a reduced form MGARCH, instead, we model contemporaneous structural interactions between concurrently trading markets using an extension to the work of Caporale et al. (2005) and Rigobon and Sack (2004) on identification via heteroskedasticity. Within the framework we allow different regimes, corresponding to periods of tranquility and to a series of crises experienced during the sample period. One advantage of our structural GARCH approach is that the model identifies the underlying independent shocks which are key to sourcing transmissions between asset markets.

We also implement an innovative approach to classifying and interpreting structural shocks by attributing them to a specific source market using variance decompositions. Unlike previous approaches, this method is data-driven and does not rely on arbitrary restrictions such as market hierarchies, orthogonalizations or chronology. Once we have matched structural shocks to their market of origin, it becomes possible to track the size and duration of innovations from any particular source and compare their relative importance under different regimes (that is in the different crises or tranquil periods). The rich interactions captured in our model contribute to the developing empirical literature on cross-country and cross-asset-market crisis models. In addition, our technique can be applied to other crises where the source of trouble is unclear, enabling observers to distinguish the real underlying drivers of contagion from simple crisis chronology.

Data from the Asian crisis of 1997-1998 offers a tangle of interrelated information flows between regional markets; we can untangle key elements of crisis transmission using our structural model. Taking the perspective of an international investor, we model daily U.S. dollar returns to major equity market indices during the crises in Asia over the period 1997-1998. The sample consists of Hong Kong, Indonesia, Korea and Thailand, each of which had their own crises and potentially also received transmissions from other crisis countries. The results show statistically significant contagion between a number of countries and some evidence for hypersensitivity. Not all significant crisis changes were associated with increases in market integration; several linkages weakened. Our findings are consistent with the hypothesis that in many cases the crisis country had 
weak incentives to slow down the spread of turbulence to neighbors, while nearby markets under the threat of contagion had more cause to take a proactive role in curbing the crisis of an affected neighbor, or once a crisis has developed, to look for protection either via domestic regulation or international policy coordination.

Further analysis using innovation accounting for an equally-weighted portfolio of equity indices shows the rise in importance of Korean and Hong Kong-sourced shocks as transmitters of contagion in the region, a reaction made more marked by the Hong Kong market's hypersensitivity to news from Indonesia during October 1997. The cross market effects revealed by impulse responses on covariances between assets show how the covariances between non crisis countries can be affected by the events unfolding elsewhere.

The paper begins with a brief review of the modelling of contagion, the difficulties this presents for policy makers in using the results, and how this motivates the current paper. In Section 3 we set out the modelling strategy and Section 4 explains the dynamic analysis. The Asian data and estimation results are reported in Sections 5 and 6 . Section 7 concludes.

\section{Motivation}

Crisis-driven changes in the transmission of asset market shocks are often labelled contagion. Theoretical models of contagion have emphasized the role of information flow, (Akhigbe and Madura, 2001), portfolio rebalancing (Kodres and Pritzker, 2002) and institutional linkages (Allen and Gale, 2000). Most recently, the linkages created through networks in international banking have come to attention as a means of transmitting crises through financial institutions; for an overview see Allen and Babus (2008).

Empirical contagion models aim to measure these changes in the relationships between asset markets. For example Rigobon (2001) emphasizes increased correlations. This may come through increased strength of existing linkages, as in Egloff et al. (2007) who investigate microstructural channels when looking at credit risk transmission, or via changes in the parameters connecting assets, such as Yang et al. (2009). Alternatively, contagion may be viewed as the opening of new channels of transmission during crisis, see Dungey and Martin (2007). Other authors emphasize nonlinearities and use threshold models 
to separate tranquil and crisis periods; such as Bae et al. (2003) and Billio and Pelizzon (2005) or more recently the potential for a domino effect of crises in Markwat et al. (2009). An acknowledged aspect of each of these approaches is the need to first control for general conditions, such as in Giesecke and Weber (2004) who control for common effects in credit default contagion, Dungey and Martin (2007) who use a common factor approach and Egloff et al. (2007) who differentiate macrostructural channels.

Crisis prevention and mitigation is a key goal of financial regulators. Suggestions for mitigating or preventing crises include Diamond and Dybvig (1983), who argue for deposit insurance to stop runs, and Castiglionesi (2007), who argues that central banks can use reserve requirements to compensate for the incomplete contracts which allow contagion to exist. ${ }^{3}$ Network theory proposes optimal degrees of connectedness between financial institutions, where both the number of connections and the form of those connections whether to the centre or periphery institutions - matters. (See Allen and Gale (2000) for the seminal contribution but also Frexias et al. (2000), Hasman and Samartin (2008), and for empirical evidence, Furfine (2003).)

Knowing how to respond to a crisis depends on more than simply knowing that contagion exists, or measuring the size of these effects, although these are undoubtedly important aspects. To formulate an appropriate crisis response it is also critical to be able to trace the source of the crisis. For example, the Bank of England, viewing constraints on the economy as emerging from the banking sector, provided financial support to improve banks' balance sheets in order to tackle reduced credit to businesses and households. Thus far, the empirical literature on financial contagion has not addressed this issue, but simply identifies changes in the relationship between markets.

Here we provide a method for identifying both the existence of contagion between markets, and to identify the direction of transmission. We distinguish between contagion, which is the impact of a crisis in one market on another non-crisis market, and hypersensitivity, which is the increased sensitivity a market in crisis experiences to externally generated shocks. The distinction between contagion and hypersensitivity is important

\footnotetext{
${ }^{3}$ Note that the Castiglionesi (2007) model has an acknowledged moral hazard problem.
} 
for policy making. If a market is in crisis, it is most likely that domestic policy makers are more concerned about hypersensitivity than contagion - that is they are concerned about the increased reaction of the domestic economy to foreign shocks during this time, and less concerned about the effects of their own crisis on others. On the other hand, foreign countries who are not experiencing a crisis are concerned mainly about limiting the spread of the crisis and hence about the effects of contagion. This highlights an important tension in forming international agreements on crisis management - the incentives of the crisis and non-crisis countries are quite different. In the Asian financial crisis of 1997-1998, for example, the actions of Malaysia in limiting capital flows from the end of August 1998 is a good example of a country concerned with limiting hypersensitivity, while the IMF programs of the time can be portrayed as attempts to limit contagion to developed markets. In this paper we look to the empirical separation of these effects.

\section{Modelling strategy}

Consider a vector of $k$ filtered asset returns $\mathbf{Y}_{t}$, which are all potentially contemporaneously interlinked in tranquil periods, so that the system can be described as

$$
\mathrm{BY}_{t}=\mathbf{u}_{t}
$$

where $\mathbf{B}$ is a $k \times k$ matrix of coefficients representing these non-crisis linkages, $b_{i j}$, normalized on the diagonal elements of $\mathbf{B}$. The filter removes non-zero means, auto-correlation, spillovers, and contemporaneous common factors. A typical choice of filter is a $\operatorname{VAR}(1)$ in returns with the US short term interest rate as an exogenous variable representing global financial conditions; see Forbes and Rigobon (2002). The $k \times 1$ vector $\mathbf{u}_{t}$ represents the idiosyncratic shocks in the system,

$$
\begin{aligned}
& \mathbf{u}_{t}=\mathbf{g}_{t} \varepsilon_{t} \\
& \varepsilon_{i t} \sim i i d N(0,1)
\end{aligned}
$$

where $\mathbf{g}_{t}$ is a $k \times k$ diagonal matrix. (Scaled structural innovations $\mathbf{u}_{t}$ are uncorrelated.) The underlying shocks themselves, given by $k \times 1$ vector $\varepsilon_{t}$, are distributed i.i.d. standard 
normal. Appendix A gives a detailed $k=2$ dimensional example of the model and dynamics.

Here, we capture hypersensitivity and contagion as a change in the strength of linkages between asset returns during a crisis consistent with the approach of Forbes and Rigobon (2002), Favero and Giavazzi (2002), and Pesaran and Pick (2007) amongst others. ${ }^{4}$ (These additional parameters can also detect nonlinearities in the mean equations associated with the crises.) We explicitly model both the ability of countries to transmit contagion abroad and any super-sensitivity to foreign shocks during periods of domestic crisis. In the past, these two effects have not been separately distinguished nor empirically quantified, both being captured in a single measure. We model tranquil and crisis periods as follows:

$$
\left(\mathbf{B}+\mathbf{B}_{\mathbf{c}} \mathbf{D}_{\mathbf{t}}+\mathbf{D}_{\mathbf{t}} \mathbf{B}_{\mathbf{s}}\right) \mathbf{Y}_{t}=\mathbf{B}^{*} \mathbf{Y}_{\mathbf{t}}=\mathbf{u}_{t},
$$

with $\mathbf{B}_{\mathbf{c}} \mathbf{D}_{\mathbf{t}}$ and $\mathbf{D}_{\mathbf{t}} \mathbf{B}_{\mathbf{s}}$ representing the linkages present in crisis periods. Contagion (indicated by subscript $c$ ) is modelled as the additional impact on the asset market in home country $i$ during a crisis in foreign country $j$, given by the parameters $b_{c, i j}\left(b_{c, i i}=0\right)$ in each equation, the elements of the $k \times k$ matrix $\mathbf{B}_{\mathbf{c}}$. Hypersensitivity (indicated by subscript $s$ ), is given by the parameter $b_{s, i j}$ in each equation (elements of the $k \times k$ matrix $\mathbf{B}_{\mathbf{s}}$ ) measuring the additional impact of foreign shocks during a domestic crisis. Each period of crisis is identified using an indicator variable $D_{i, t}$ which is one during the crisis in home country $i$ and zero otherwise, elements of the $k \times k$ diagonal matrix $\mathbf{D}_{\mathbf{t}}$. The relevance of each instance of contagion and hypersensitivity is tested by the significance of the parameters $b_{c, i j}$ and $b_{s, i j}$ respectively. In the case of no contagion or hypersensitivity in the system $b_{c, i j}=b_{s, i j}=0$ for all $i, j$.

\footnotetext{
${ }^{4}$ Choice of crisis periods is described in section 5 below.
} 
The detailed structure of equation (4) is

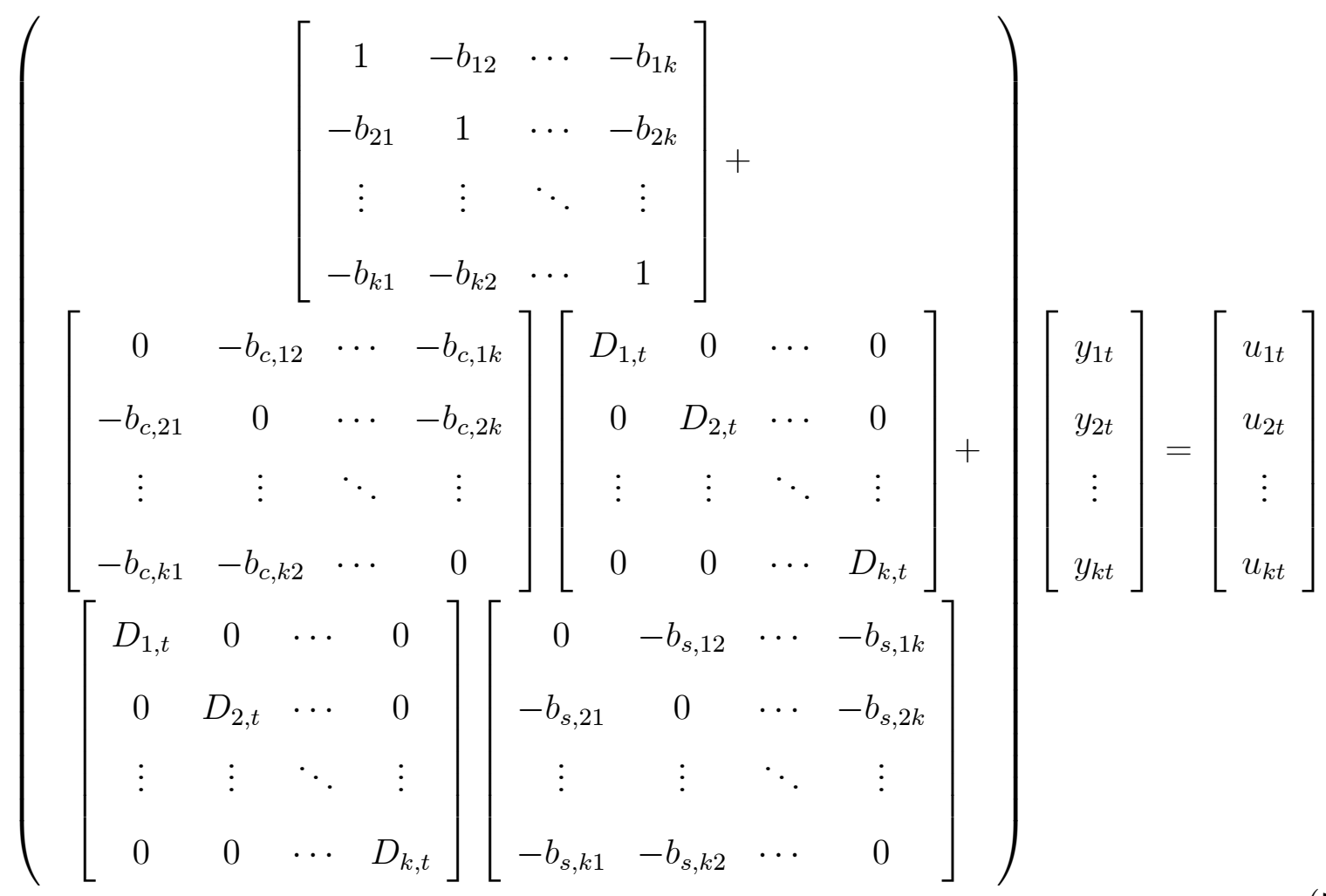

and for each $i$

$$
y_{i t}=\sum_{j=1, j \neq i}^{k} b_{i j} y_{j t}+\sum_{j=1, j \neq i}^{k} b_{c, i j} D_{j t} y_{j t}+\sum_{j=1, j \neq i}^{k} b_{s, i j} D_{i t} y_{j t}+u_{i t} .
$$

We also model the known volatility clustering of financial markets returns in $\mathbf{Y}_{t}$. Given the structure of (2) to (4) it is straightforward to see that

$$
\mathbf{B}^{*} \mathbf{Y}_{t} \sim\left(0, E\left[\mathbf{G}_{t}\right]\right)
$$

where $\mathbf{G}_{t}=\mathbf{g}_{t} \varepsilon_{t} \varepsilon_{t}^{\prime} \mathbf{g}_{t}^{\prime}$ is a $k \times k$ diagonal matrix of the squares of the elements of the $\operatorname{matrix} \mathbf{g}_{t}$.

The conditional covariance matrix of the structural shocks is a $\operatorname{GARCH}(1,1)$, specified for $\mathbf{G}_{t}$ as

$$
\mathbf{G}_{t}=\operatorname{diag}\left[\boldsymbol{\psi}+\boldsymbol{\lambda}\left(\mathbf{u}_{t-1} \circ \mathbf{u}_{t-1}\right)\right]+\boldsymbol{\zeta} \mathbf{G}_{t-1},
$$

where $\boldsymbol{\psi}$ is a $k \times 1$ vector of constants, $\psi_{i}, \boldsymbol{\lambda}$ is a $k \times k$ diagonal matrix of ARCH coefficients 
and $\boldsymbol{\zeta}$ is a $k \times k$ diagonal matrix of GARCH coefficients. So for each country $i$

$$
g_{i i, t}^{2}=\psi_{i}+\lambda_{i i} u_{i, t-1}^{2}+\zeta_{i i} g_{i i, t-1}^{2}
$$

Since both $\mathbf{G}_{t-1}$ and $\mathbf{u}_{t-1}$ are unobservable, we specify the system as a reduced form,

$$
\mathbf{Y}_{t}=\boldsymbol{\kappa}_{t}, \text { where } \boldsymbol{\kappa}_{t}:=\left(\mathbf{B}^{*}\right)^{-\mathbf{1}} \mathbf{u}_{t}=\mathbf{A} \mathbf{u}_{t}
$$

The joint conditional distribution of the vector of filtered returns is

$$
\mathbf{Y}_{t} \sim N\left(0, \mathbf{H}_{t}\right)
$$

and we work with this reduced form covariance matrix, $\mathbf{H}_{t}$, which can be estimated as a multivariate GARCH process in the filtered returns vector $\mathbf{Y}_{t}, \mathbf{H}_{t}=\mathbf{A G}_{\mathbf{t}} \mathbf{A}^{\prime}$.

Identification of the structural parameters in $\mathbf{B}^{*}$ from the estimated value of $\mathbf{H}_{t}$ depends on establishing the link between the structural parameters and the reduced form. The lower diagonal elements of the reduced form covariance matrix $\mathbf{H}_{t}$ can be expressed as $^{5}$

$$
\operatorname{vech}\left(\mathbf{H}_{t}\right)=\mathbf{C}_{0}+\mathbf{C}_{1}\left(\boldsymbol{\kappa}_{t-1} \circ \boldsymbol{\kappa}_{t-1}\right)+\mathbf{C}_{2} \mathbf{h}_{t-1}
$$

where $\mathbf{C}_{0}$ is a $k(k+1) / 2 \times 1$ vector of constant coefficients, $\mathbf{C}_{1}$ is a $k(k+1) / 2 \times k$ matrix of $\mathrm{ARCH}$ coefficients, $\mathbf{C}_{2}$ is a $k(k+1) / 2 \times k$ matrix of GARCH coefficients and $\mathbf{h}_{t}$ is a $k \times 1$ vector of the diagonal elements of $\mathbf{H}_{t}$.

To establish the relationship between the coefficients of $\mathbf{H}_{t}$ and the structural parameters we begin with the vector of ARCH terms. Relying on the independence of structural shocks, we set cross products to zero and write

$$
(\mathbf{A} \circ \mathbf{A})^{-1} \boldsymbol{\kappa}_{t-1} \circ \boldsymbol{\kappa}_{t-1}=\left(\mathbf{u}_{t-1} \circ \mathbf{u}_{t-1}\right) .
$$

\footnotetext{
${ }^{5}$ In the case of non-zero mean data the following expressions would be complicated by the additional interactions of any common factors with the independent factors.
} 
Next we can make a similar transformation of the GARCH terms:

$$
(\mathbf{A} \circ \mathbf{A})^{-1} \mathbf{h}_{t-1}=\operatorname{vecd}\left(\mathbf{G}_{t-1}\right)
$$

where vecd is the vector of the diagonal elements of the matrix.

If we again rewrite $\mathbf{H}_{t}=\mathbf{A G}_{\mathbf{t}} \mathbf{A}^{\prime}$ in vech $(\cdot)$ form and define the required transformation of the $\mathbf{A}$ matrix as $\mathbf{A}^{v}$, a $k(k+1) / 2 \times k$ matrix of products of the elements of $\mathbf{A}$, then the reduced form covariance matrix is comprised of structural shocks and structural parameters,

$$
\operatorname{vech}\left(\mathbf{H}_{t}\right)=\mathbf{A}^{v} \boldsymbol{\psi}+\mathbf{A}^{v} \boldsymbol{\lambda}\left(\mathbf{u}_{t-1} \circ \mathbf{u}_{t-1}\right)+\mathbf{A}^{v} \boldsymbol{\zeta} \operatorname{vecd}\left(\mathbf{G}_{t-1}\right) .
$$

Finally by substituting equation (13) and equation (14) we can link the $\mathbf{C}$ matrices of the reduced-form MGARCH and the structural parameters,

$$
\operatorname{vech}\left(\mathbf{H}_{t}\right)=\mathbf{A}^{v} \boldsymbol{\psi}+\mathbf{A}^{v} \boldsymbol{\lambda}(\mathbf{A} \circ \mathbf{A})^{-1}\left(\boldsymbol{\kappa}_{t-1} \circ \boldsymbol{\kappa}_{t-1}\right)+\mathbf{A}^{v} \boldsymbol{\zeta}(\mathbf{A} \circ \mathbf{A})^{-1} \mathbf{h}_{t-1} .
$$

Estimation and identification of structural form parameters therefore depends on the estimation of the reduced form covariance matrix expressed in terms of structural parameters. The coefficients from the reduced form in equation $(12)$ provide $k(k+1) / 2$ parameters in the $\mathbf{C}_{0}$ matrix, $k^{2}(k+1) / 2$ parameters in each of the $\mathbf{C}_{1}$ and $\mathbf{C}_{2}$ matrices for a total of $(2 k+1)(k+1) k / 2$. The structural model contains $3 k(k-1)$ parameters in the $\mathbf{B}^{*}$ matrix and $3 k$ GARCH parameters for a total of $3 k^{2}$. (In the four-country example estimated below there are 48 structural parameters and 90 reduced form parameters, unlike a conventional identification problem where the number of structural parameters typically exceeds the number of reduced form moment conditions.)

The MGARCH structure of the model provides us with additional scores (first order conditions) that overcome problems of identification and endogeneity. Overcoming the endogeneity problem of this simultaneous model is possible due to the fact that we do not directly estimate the contemporaneous structural model but indirectly estimate struc- 
tural parameters as part of the time-varying reduced form covariance matrix. There is no endogeneity problem in the estimation of the reduced form covariance matrix. Structural parameters are non-linear transformations of the reduced form parameters in this model, and although an analytical proof of identification is difficult, we have evidence for local numerical identification since we consistently achieve convergence in the maximization of the structural likelihood function from a range of starting values. ${ }^{6}$ Numerical identification of the structural parameters is helped by low correlation between the filtered returns series. We also confirm the numerical identification and optimization procedure by estimating the model from simulated data.

\section{Dynamics}

Innovation accounting within the SGARCH model gives a mapping of the dynamics of transmissions between markets. We introduce a new approach to connecting each structural shock to a source market without resorting to standard identifying restrictions such as Choleski decomposition or long-run variance assumptions. Our method relies on an interpretation of variance decomposition: we treat the shocks which contribute the largest part of each domestic-market forecast error variance during the tranquil period as emanating from that market. This interpretation is possible because we estimate the entire (normalized) structural model and can thus work with the structural innovations directly, rather than their reduced form counterparts. Consequently we do not need to apply arbitrary restrictions to the structural model to trace turbulence during crises back to a specific source.

We make tranquil period dynamics the benchmark then examine the dynamics of both contagion and hypersensitivity effects during periods of crisis. We take the position of an international investor holding an equally weighted USD portfolio of each of the market indices in the model, and track the impact of structural impulses on the volatility of this naive portfolio. While this is a convenient application of the processes and effects, the

\footnotetext{
${ }^{6}$ Rothenberg (1971, Theorem 7) shows that for non-linear systems of equations, under weak regularity conditions, an 'overly strong sufficiency condition' for global identification of structural parameters is met when the Jacobian matrix of partial derivatives with respect to the structural parameters has a positive determinant and the sum of the Jacobian and its transpose is positive semidefinite.
} 
potential for exploring contagion dynamics in this model are much wider than this simple portfolio example. The model can be used to track individual transmission paths for shocks from all domestic and foreign sources under each of the four crises in the sample, separating hypersensitivity and contagion effects. ${ }^{7}$

The 1-step ahead conditional forecast error variance for $\mathbf{Y}_{t}$ is the fitted value of the reduced form conditional covariance matrix:

$$
\begin{aligned}
\operatorname{var}_{t}\left[\mathbf{Y}_{t+1}-E_{t}\left(\mathbf{Y}_{t+1}\right)\right] & =\operatorname{var}_{t}\left[\mathbf{A} \mathbf{u}_{t+1}-E_{t}\left(\mathbf{A} \mathbf{u}_{t+1}\right)\right] \\
& =\mathbf{H}_{t+1 \mid t}
\end{aligned}
$$

treating all estimated parameter values as known with certainty.

The conditionally heteroskedastic properties of the model mean that forecast errors vary with realized volatility at time $t$, and consequently each forecast error depends on the specific history of volatility at time $t$ and more generally on the forecast horizon (Gallant et al. 1993 and Engle and Ng 1993). Since this process generates almost as many forecast errors at the 1-step horizon as there are observations in the sample, we need a way of summarizing the information without losing the value of conditioning. Here we compute the forecast errors for both tranquil and crisis periods for each time $t$, and stack them by size, creating an empirical distribution of conditional forecast error variances, effectively based on a series of random draws from the structural error distributions. We then select empirical quantiles from the tranquil and crisis period distributions and compare the forecast error variances and decompositions.

The forecast error variance is a non-linear function of structural parameters and structural shocks, however the identification of structural parameters during estimation means that it is possible to numerically identify the structural errors via the relationship $\mathbf{B}^{*} \mathbf{Y}_{t}=\mathbf{g}_{t} \varepsilon_{t}$ so that $\mathbf{g}_{t}^{-1} \mathbf{B}^{*} \mathbf{Y}_{t}=\varepsilon_{t}$. The percentage of the forecast error variance at time

\footnotetext{
${ }^{7}$ One could ask, for example, 'What is the effect on the volatility path of returns to the Thai stock market of a shock emerging from Hong Kong, during the Indonesian market crisis?', and derive an impulse response function to estimate the size and duration of this specific effect.
} 
$t, V D_{i, j \mid t}$, for market return $y_{i}$ that is due to each structural shock $\varepsilon_{j}$ is computed as

$$
V D_{i, j \mid t}=\frac{\left(\mathbf{A g}_{j, t+1 \mid t} \mathbf{g}_{j, t+1 \mid t}^{\prime} \mathbf{A}^{\prime}\right)_{i i}}{\left(\mathbf{A} \mathbf{g}_{t+1 \mid t} \mathbf{g}_{t+1 \mid t}^{\prime} \mathbf{A}^{\prime}\right)_{i i}} \times 100
$$

where $\mathbf{g}_{j, t+1 \mid t}$ is the $j$ th column of the 1 -period ahead forecast standard deviation matrix $\mathbf{g}_{t+1 \mid t}$. Each of the structural shocks $\varepsilon_{j}$ is linked to the $i t h$ market if

$$
V D_{i, j \mid t}>V D_{i, m \mid t} \text { for } m=1, \ldots, k, m \neq i .^{8}
$$

Further, in the event that an investor holds an equally-weighted portfolio across the $k$ markets, the forecast error variance decomposition for the portfolio indicates the shift in portfolio risk associated with exposure to a particular market during a crisis. The proportion of portfolio volatility associated with each structural shock component can be computed as

$$
V D_{p, j \mid t}=\frac{w^{\prime} \mathbf{A g}_{j, t+1 \mid t} \mathbf{g}_{j, t+1 \mid t}^{\prime} \mathbf{A}^{\prime} w}{w^{\prime} \mathbf{A} \mathbf{g}_{t+1 \mid t} \mathbf{g}_{t+1 \mid t}^{\prime} \mathbf{A}^{\prime} w} \times 100
$$

where $w$ is a $k \times 1$ vector of portfolio weights, in our example, $1 / k$. Using (20) we can compare the mean contribution of each shock to portfolio variance during the tranquil and crisis periods.

Conditional impulse responses for the variance of the individual returns can be computed using the approach of Lin (1997). For the equally-weighted portfolio the response is the expectation at time $t$ of the partial derivative of $w^{\prime} \mathbf{H}_{t+n} w$ with respect to $\varepsilon_{j, t}^{2}$, given by

$$
E_{t}\left[\frac{\partial w^{\prime} \mathbf{H}_{t+n \mid t} w}{\partial \varepsilon_{j, t}^{2}}\right]=E_{t}\left[w^{\prime} \mathbf{A} \frac{\partial \mathbf{G}_{t+n \mid t}}{\partial \varepsilon_{j, t}^{2}} \mathbf{A}^{\prime} w\right] .
$$

The conditional impulse response of individual components $(i j)$ of the portfolio covariance matrix is computed as

\footnotetext{
${ }^{8}$ This ordering would not be complete or unique if there were more than one market to which the shock $\varepsilon_{j}$ contributed the majority of forecast error variance or if any two structural shocks accounted for the same proportion of variance for one market. Neither of these cases arise in this application.
} 


$$
E_{t}\left[\frac{\partial \mathbf{H}_{t+n \mid t}}{\partial \varepsilon_{j, t}^{2}}\right]_{i j}=E_{t}\left[\mathbf{A} \frac{\partial \mathbf{G}_{j, t+n \mid t}}{\partial \varepsilon_{j, t}^{2}} \mathbf{A}^{\prime}\right]_{i j} .
$$

Using the same method as for the variance decompositions, we compute an impulse response conditioning on each time $t$ volatility history, stack each time path into an empirical distribution and draw out specific quantiles for comparison.

\section{The Asian crisis}

During 1997-1998 there were multiple crises in a number of countries in Asia across several different classes of assets. The debate over the causes of, and links between, these crises remains unresolved.

The discursive literature at the time of the Asian crisis viewed pressure in the Hong Kong equity market around October 1997 as leading to pressure on equity markets in other countries, and particularly in precipitating crisis in Korean markets. Four of the major countries involved in the turmoil during 1997-1998 were Thailand, Indonesia, Korea and Hong Kong. However empirical evidence on contagion during this period is mixed. On one hand, Forbes and Rigobon (2002) find little evidence for contagion in these equity markets using bivariate correlation tests, and Bekiros and Georgoutsos (2008b) reach a similar conclusion using an extreme value approach. On the other hand, each of Baig and Goldfajn (1999), Caporale et al. (2003) and Baur and Schulze (2005) find statistically significant contagion effects. Markwat et al. (2009) use ordered logit models to identify a domino effect where local crisis evolve into more widespread and severe events and Candelon et al. (2008), using multivariate synchronization indexes, find a sudden increase in bull and bear market synchronization among Asian stock markets in 1997. However the dynamic properties of the SGARCH model set out above allow us to go further than testing for contagion effects. We can also identify the main sources of turbulence for each country's crisis and gauge their relative importance to a diversified investor.

We construct returns as the residuals from a $\operatorname{VAR}(1)$ on the log changes in the daily US dollar-valued equity market indices for each country, including also the contemporaneous 
3-month US Treasury Bill rate as a proxy for an exogenous common shock, following Forbes and Rigobon (2002). ${ }^{9}$ The full sample runs from 2 January 1992 to 9 January 2007. Figure 1 shows the time series of returns.

The model proposed in Section 3 requires an exogenous identification of the indicator variables, $D_{i}$ for $i=1, \ldots, k$, where $k$ is the total number of equity indices involved so we collate crisis dates for each individual country from existing sources. We set the Hong Kong crisis period as 27 October 1997 to 17 November 1997 (Billio and Pelizzon, 2003; Rigobon, 2003) and the Indonesian crisis period as 1 January 1998 to 27 February 1998 encompassing the period of high volatility in returns associated with political uncertainty and IMF negotiations. The Korean crisis occurs in the lead up to successful renegotiation of its debt moratorium with the IMF on 24th December 1997. Clearly (Panel C in Figure 1) the volatility in this market began in late November; we designate the Korean crisis period from 25 November 1997 to 31 December 1997. The Thai crisis in equity markets dates from 10 June 1997 to 29 August 1997 (Billio and Pelizzon, 2003; Rigobon, 2003). The crisis periods are shown as the narrow shaded areas in each of the panels of Figure 1.

Table 1 gives data sources and some descriptive statistics for the returns series. The first panel is for the entire sample, showing that filtering does not remove the nonnormality in the data and motivating the use of a structural GARCH model for the filtered residuals to captured volatility clustering and fat tails. The following four panels give the crisis periods chronologically, confirming that, in general, the volatility of returns rises when a market is in crisis.

Our modelling strategy depends on the preservation of higher order dynamics in the VAR residuals, so we tested the returns series for dependence and nonlinearity before and after VAR filtering. Following Kyrtsou and Serletis (2006) and Bekiros and Georgoutsos (2008a), we applied the BDS test (Brock et al. 1996) for time-based dependence (independent and identically distributed observations), the Tsay (1986) test for quadratic

\footnotetext{
${ }^{9}$ Data sources are listed in the notes to Table 1. Before estimation we removed all observations where any market was not trading. This reduced the number of observations in the sample period from 3951 to 3607 .
} 
serial dependence in means, the Engle (1982) LM test for nonlinearity in the variance, and the Hinich (1982) bispectrum test for nonlinearity and Gaussianity. All tests reject the nulls of independence and linearity before and after VAR filtering suggesting that only linear dependence and the common shock have been removed. ${ }^{10}$ Table 2 reports significance levels (p-values) for the Tsay, Engle and Hinich tests and Table 3 shows results for the BDS (Brock et al. 1996).

\section{Estimation results}

Tables 4 to 6 gives the results of applying the model of Section 3 to the Asian dataset. We estimate using quasi-maximum likelihood techniques (QML) via numerical methods in Ox. Figure 2 sets out graphical evidence for model fit, showing the standardized residuals for each market and Table 2 reports p-values for tests for linear and non-linear dependence and Gaussianity. The model accounts for much of the conditional heteroskedasticity, skewness and kurtosis of the original filtered series seen in Figure 1, although some nonnormality remains as evidenced by the Hinich test results, and we observe a few large outliers associated with specific market events. ${ }^{11}$ Testing failed to find any significant ARCH effects in any of the standardized residuals series. The Tsay and Hinich tests for linearity in means are not rejected at the $5 \%$ level for Hong Kong, Indonesia and Thailand standardized residuals but the results are somewhat weaker for Korea. Table 3 shows p-values for the BDS test which fail to reject pure randomness for all but the Indonesian residuals. We view these results with caution given the problems with test size and interpretation that can arise when applying this test to the residuals of a non-linear model. (See Brooks and Heravi 1999, and Brooks and Henry 2000.)

\footnotetext{
${ }^{10}$ We also fitted a multivariate Mackey-Glass model (Kyrtsou and Labys 2006) as an alternative to the $\operatorname{VAR}(1)$ but found no substantial difference to the filtered residuals and so selected the simpler VAR(1) model. Results for the Mackey-Glass filter are available from the authors on request.

${ }^{11}$ The large outlier in March 1996 in the Hong Kong series shows the significant falls in this market and through the region due to concerns over China. A number of events appear to be linked with the outliers for the Indonesian returns, including the opening of the market to full foreign ownership in October 1993, general regional volatility in April 1998, the Bali bombings in October 2002 and political uncertainty combined with major earthquakes in May 2006. The September 11 attacks show up in the outlier in the Korean series and a panic over currency regulations in December 2006 creates an outlier in the Thai series. Model estimation is robust to the removal of these large outliers. We do not report results separately here but they are available from the authors on request.
} 
Table 4 shows the tranquil period coefficient estimates. There are significant linkages between a number of the equity markets. The reported coefficients show the impact of returns from the markets in the table row on the corresponding column market return. Reading down each column, the returns to the Hong Kong index exhibit a significant positive relationship with returns in Indonesia, (0.086) and Korea (0.296). Indonesian returns are also significantly affected by Hong Kong (0.103) while the Korean returns are positively related to Indonesia's (0.148) but negatively related to Hong Kong's ( -0.125$)$ during periods of tranquility. The Thai market appears to import a positive impact from all three neighbors in the tranquil period, but does not influence the other markets (as evident in the last row of Table 4).

Hypersensitivity occurs when the connections between domestic markets and foreign markets change during a domestic crisis period (Table 5). The coefficients in this table represent the impact due to crises in markets in the column headings but felt via the returns from (non-crisis) markets in the rows, hence 'hypersensitivity'. Only one linkage is statistically significant and positive in Table 5. This represents positive hypersensitivity of the Hong Kong market to Indonesian returns (0.814) during the Hong Kong crisis. Two more linkages are significant and negative. Korean returns covaried negatively with Indonesian returns during the Korean crisis $(-0.753)$ and that Hong Kong returns varied negatively with Korean returns during the Hong Kong crisis, (-0.751).

The negative coefficients represent an interesting addition to the literature, in that they suggest that during periods of crisis, links between two markets may move in either direction. This is consistent with Forbes and Rigobon (2002) who find a fall in conditional correlation in many instances, and with the network literature where reduced linkages during crises are also consistent with lower correlation.

Contagion occurs when a local market is affected by crisis in other countries. Table 6 shows the strength of these effects. In this table contagion effects arise from crises in the row markets and impact on returns to the (non-crisis) column market. Results show that Indonesia experienced contagion from Korea during the Korean crises (0.727). During the Hong Kong crisis (first row of the table), Korea experienced significant positive contagion 
effects from Hong Kong (0.665) while Thailand was impacted negatively by Hong Kong returns $(-0.504)$.

Table 7 provides the parameter estimates for the GARCH behavior of the underlying shocks. In each of the cases there is a small positive and significant constant and significant $\mathrm{ARCH}$ and $\mathrm{GARCH}$ effects. The combined $\mathrm{ARCH}$ and $\mathrm{GARCH}$ parameters sum close to one in each case.

A likelihood ratio test of the hypothesis that all hypersensitivity and contagion dummies are zero yields a test statistic of $78.24 \sim \chi_{24}^{2}$ which has a p-value close to zero.

In summary we find evidence for shifts in the relationships between the equity markets of Hong Kong, Indonesia, Korea and Thailand during the crisis period, but these effects are not uniform in direction or significance across countries and crises. In terms of strengthening effects, the Hong Kong crisis had a large impact on regional markets, generating significant contagion in Korea but creating a weakening link with Thailand, where correlation fell (Table 6). During the Hong Kong crisis in October 1997, the Hong Kong market also became less sensitive to news from Korea but more sensitive to news from Indonesia (Table 5). Combining the results reported in Tables 5 and 6, it is apparent that the Korean crisis later that year transmitted additional turbulence to Indonesia, but at the same time returns from Indonesia became significantly less influential for the Korean market, possibly suggesting that the domestic turmoil both created trouble for the neighboring market and drowned out feedback from outside. We observe this same effect in relation to Hong Kong and Korea. During the Hong Kong crisis Korea receives significant positive contagion (0.665) but Korean returns are dampened into Hong Kong $(-1.981$ in Table 5$)$. By way of contrast, the signs on the contagion and hypersensitivity parameters connecting Hong Kong and Indonesia indicate an amplification in both directions: the Hong Kong crisis had significant positive contagion effects on Indonesia (0.103 in Table 6) but returns in Indonesia also had a significant positive hypersensitivity effect on Hong Kong during the Hong Kong crisis (0.814 in Table 5). The linkages between markets clearly take a number of forms and their interaction displays a complexity previously not disentangled. 


\subsection{Variance decomposition}

The first panel of Table 8 gives the tranquil period decomposition at one step ahead, with 5th and 95th quantile measures. ${ }^{12}$ We use these results to allocate the shocks to their source market. In each case, we label the shock that makes the greatest contribution to volatility in each of the tranquil-period decompositions as the own-country shock. ${ }^{13}$ The columns in the table refer to the volatility in each asset (or portfolio), and the rows to the contributing sources of shock. Own-country shocks contribute at least $80 \%$ of forecast error variance in each case. The maximum impact from another country at the mean is 17\% (the link from Korean shocks to the Hong Kong market). The final column in Table 8 gives the variance decompositions for the equally weighted portfolio which also account for covariance between the returns. In the tranquil period, Korean and Indonesian shocks are dominant, at $39 \%$ and $31 \%$ of the total whereas Hong Kong and Thailand contribute around $15 \%$ each.

The second panel of Table 8 shows the variance decompositions relating to links due to hypersensitivity during crisis periods. ${ }^{14}$ There are substantial changes from the tranquil period. The contribution of domestic shocks is diminished and the impact of Indonesia increases commensurately. For Hong Kong, Indonesian shocks dominate the local effect, contributing half the forecast error variance. For the equally-weighted portfolio, results show an increased contribution of 30 percentage points from Indonesia (60\%) and about 5 percentage points more from Hong Kong. The contribution from Korea is reduced, most likely due to the changing link between Indonesia and Korea.

During an external crisis, contagion links also create dramatic changes. The third panel of Table 8 shows that the contribution of domestic market shocks to the one-stepahead variance decomposition is reduced under foreign crises compared with the tranquil period for three of the four markets. Change is most dramatic for Indonesia where the contribution from domestic shocks drops by 57 percentage points to a mean contribution

\footnotetext{
${ }^{12}$ The variance decomposition is constructed for all $t$ possible conditionings in the sample. A histogram of these outcomes gives the mean and quantiles reported in Table 8.

${ }^{13}$ The results at 5 steps ahead confirm our classification.

${ }^{14}$ All insignificant parameters are set to zero when variance decompositions and impulse response functions are computed.
} 
of $42 \%$; contagion from Korea (46\%) and Hong Kong (12\%) account for this. The contribution of the domestic shock for Hong Kong falls by about 10 percentage points to $71 \%$ in favour of an increase in Korean contribution to $26 \%$. The contribution of domestic shocks for Korea decreases by about 17 percentage points, and the influence of Hong Kong rises from less than $1 \%$ to $15 \%$. There is no real change in the Thai decomposition. Hence, Hong Kong and Korean shocks are clearly important in all countries apart from Thailand. This is also evident in the portfolio results, where the contribution of Hong Kong increases by 7 percentage points to $22 \%$ and the Korean contribution increases to $57 \%$ due to contagion effects. However, there are falls in the percentage contributions of Indonesia and Thailand to portfolio variance.

\subsection{Impulse response functions}

Figure 3 presents impulse responses in the variance of the equally weighted portfolio to unit (one standard deviation) shocks from Hong Kong, Indonesia, Korea and Thailand respectively. The left column shows the impulse response in the tranquil period, and the right column shows the responses with contagion effects. Using the unconditional (sample) portfolio variance as a basis for calculation, a 0.1 increase in portfolio variance on the vertical axis is approximately equal to a 0.6 percentage point (60 basis point) increase in annualized portfolio volatility.

A structural shock associated with Hong Kong (Panel A) in the tranquil period is the smallest of those investigated here, and takes about two months to dissipate half the initial impact. When we account for contagion, however, the effect of a one standard deviation shock is to raise variance by a factor of five over the tranquil period, with increases persisting above the initial tranquil period impact for well over three months.

Patterns for impulses to structural shocks from Indonesia (Panel B) are remarkably different. The initial impact of a one standard deviation shock in the tranquil period is much larger and the distribution of responses is also more dispersed. By contrast, contagion effects are small in this case, so that unlike Hong Kong, impulse responses for shocks from Indonesia in tranquil and contagion periods are alike though the dispersion is greater during the contagion period. 
The impact of Korean shocks (Panel C) in the tranquil period is greater than for Hong Kong, but not so large as for the Indonesian case already discussed. During the tranquil period there are statistically significant linkages with all the other countries in the sample, as shown in Table 4. The contagion effects are substantial, with the size of the initial shock in the external crisis scenario being five-fold the tranquil period shock. Half of this impact has dissipated by 45 days after the shock, but some effect is still present nearly a year after the initial shock. As a result of the lack of linkages from Thailand to other markets, the impulse responses to shocks originating from Thailand (Panel D) are small and do not change between the tranquil and contagion periods.

Overall, the largest contributors to volatility are the Hong Kong and Korean crises. Shocks from these events increase portfolio variance by between around five times and persist for a number of months.

Another way to view contagion is via impulse responses on specific covariances. Impulse responses of the equally-weighted portfolio variance average over the whole covariance matrix and can inform diversified investors, whereas responses of individual covariances detail bivariate market links rather than averaging across them, measuring contagion directly. This technique can also give a breakdown of the way interrelationships changes during a crisis.

Figure 4 shows impulse responses of four of the six covariances to a one standard deviation shock from the Hong Kong market. The array of different reactions is illuminating. Panel A shows the impulse response for the Hong Kong-Indonesia covariance. We see that the tranquil market link between the Hong Kong and Indonesian markets is weak, and a shock has a very small impact, whereas the additional contagion period channel raises covariance responsiveness by a factor of 10 and takes around two months for half the effect to dissipate. In Panel B, the impulse to the Hong Kong-Korea covariance is actually negative under normal market conditions, but crisis contagion shifts the covariance to a strong and persistent positive. By contrast, Panel $\mathrm{C}$ sets out the impulse response to the covariance between Hong Kong and Thailand. Whereas the correlation between these markets is normally positive and Hong Kong shocks tended to raise the conditional 
covariance, during the crisis the links between Thailand and the rest of the region weakened, and the response of the covariance shifts from positive to negative. Finally, Panel D shows an example of crisis-driven changes at a secondary level. The Hong Kong shock is irrelevant to the Indonesia-Korea covariance in tranquil markets but contagion creates additional transmissions amongst the markets, increasing the covariance from zero to 0.12 , even though neither of these markets is the source of the news. The remaining covariances (Indonesia-Thailand and Korea-Thailand) were very marginally affected by the Hong Kong shock, both responding slightly more negatively when affected by contagion.

The impulses of the covariances reveal some of the complexity of the linkages which occur during crises. Assessing the effects of shocks originating in one country is complicated by both the crisis market transmissions to other markets via contagion and the potential for changes in the reaction of the crisis market to information from other markets via hypersensitivity. However, there are also discernible secondary level effects so that non crisis countries experience increased covariances with each other even though the effects are not a direct impact of the news from the crisis country. These effects are realizations of the interrelatedness of the system.

\section{Conclusion}

We develop a model which contributes a refinement to the taxonomy of crises: we distinguish between hypersensitivity and contagion. A market which is in crisis may transmit that crisis towards other markets, denoted 'contagion', and it may simultaneously become more or less sensitive to the effects of shocks from non-crisis markets, denoted 'hypersensitivity'. This distinction has some importance in policy discussions. A country experiencing a crisis is likely to be concerned primarily with preventing the impact of hypersensitivity while countries which are not themselves in crisis are more concerned to prevent the spread of the crisis via contagion effects. Policy design for crisis prevention and management need to be incentive compatible with the actively operating links. This suggests that authorities require a substantial degree of discretion to actively manage crises, as their characteristics vary greatly in terms of the directions and strength of changes in linkages from tranquil to crisis periods. 
In particular, our results suggest that during the Asian crisis, the crisis countries themselves had at best weak incentives to slow the spread of turbulence, while the nearby markets had reason to look for protection either via domestic regulation or through international policy coordination.

The modelling framework separates hypersensitivity and contagion based on a multivariate GARCH framework with regimes and exogenously defined crisis periods. An advantage is that structural parameters can be identified from the reduced form. Unlike past work, which has relied on arbitrary restrictions to classify the sources of unobservable structural shocks, we use variance decompositions to label the structural shocks and connect them to source markets. This approach enables an economic interpretation of risk transmission in tranquil and crisis periods.

Applying this model to four Asian equity markets during the East Asian crisis period of 1997-1998, we observe statistically significant contagion links and hypersensitivity. Importantly, these changes are not always positive. The Thai market, for example becomes more detached from shocks from near neighbors during their crises. Hong Kong transmitted its crisis via contagion effects to both Korea and Thailand, while at the same time becoming more sensitive to news from Indonesia and less sensitive to news from Korea. Similarly, during the Korean crisis, Korea transmitted its crisis via contagion to Indonesia but simultaneously became less sensitive to Indonesian market news. From an investment perspective, decomposing the portfolio volatility of an equally-weighted portfolio of the four equity assets identifies the redistribution of sources of turbulence away from home market and towards outside. Impulse response analysis shows the increasing dominance of Korean and Hong Kong shocks during the crisis, while variance decompositions confirm this effect and also highlight heightened sensitivity to Indonesian sourced shocks during crises in other countries. An examination of the cross market linkages revealed the variety of effects operating during the crisis period.

This new framework and application contribute a breakdown of the directional effects of the relationship between asset markets during crisis. The model has a number of similarities with the recent theoretical network literature on linkages between financial 
institutions, where those institutions care about inflow from, and outflow to, counterparties; see Allen and Babus (2008) for an overview. Future work linking the empirical framework developed in this paper and network theory should provide insights into the credit crunch of 2007-2008.

\section{Acknowledgments}

We thank Andrea Cipollini, John Geweke, Tony Hall, Gordon Menzies, Adrian Pagan, Peter Phillips, Remco Zwinkels and participants at the 2007 INFINITI Conference, Trinity College Dublin, the 2008 NCER Frontiers in Financial Econometrics Workshop, Queensland University of Technology Brisbane, and an anonymous referee for helpful comments. Part of this paper was written while Thorp was a Visiting Scholar at Cambridge Endowment for Research in Finance, University of Cambridge. Thorp acknowledges the support of ARC DP0877219.

\section{Appendix A. Two-asset illustration}

Here we present a two-dimensional illustration of the main features of the model and dynamics.

The tranquil period model for VAR-filtered returns for asset markets 1 and 2, denoted by $y_{1 t}$ and $y_{2 t}$, is:

$$
\begin{aligned}
& y_{1 t}=b_{12} y_{2 t}+g_{11, t} \varepsilon_{1 t} \\
& y_{2 t}=b_{21} y_{1 t}+g_{22, t} \varepsilon_{2 t},
\end{aligned}
$$

which can be extended for crisis periods to

$$
\begin{aligned}
& y_{1 t}=b_{12} y_{2 t}+b_{s, 12} D_{1 t} y_{2 t}+b_{c, 12} D_{2 t} y_{2 t}+g_{11, t} \varepsilon_{1 t} \\
& y_{2 t}=b_{21} y_{1 t}+b_{s, 21} D_{2 t} y_{1 t}+b_{c, 21} D_{1 t} y_{1 t}+g_{22, t} \varepsilon_{2 t},
\end{aligned}
$$

where the binary dummy variables, $D_{1 t}$ and $D_{2 t}$ take the value 1 during periods of crisis experienced in $y_{1 t}$ and $y_{2 t}$ respectively, and 0 otherwise. Data in the crisis periods provide 
the extra information needed to identify the contagion parameters. For the rest of the example, we work with the simpler tranquil period model. The matrix of contemporaneous market linkages is normalized on the diagonal to give,

$$
\mathbf{B}=\left[\begin{array}{cc}
1 & -b_{12} \\
-b_{21} & 1
\end{array}\right]
$$

and

$$
\mathbf{B}^{-1}:=\mathbf{A}=\left[\begin{array}{ll}
a_{11} & a_{12} \\
a_{21} & a_{22}
\end{array}\right]
$$

The GARCH processes on $\varepsilon_{i}$ in this case are:

$$
\begin{aligned}
{\left[\begin{array}{cc}
g_{11 t}^{2} & 0 \\
0 & g_{22 t}^{2}
\end{array}\right] } & =\operatorname{diag}\left\{\left[\begin{array}{l}
\psi_{1} \\
\psi_{2}
\end{array}\right]+\left[\begin{array}{cc}
\lambda_{11} & 0 \\
0 & \lambda_{22}
\end{array}\right]\left[\begin{array}{l}
u_{1 t-1}^{2} \\
u_{2 t-1}^{2}
\end{array}\right]\right\} \\
& +\left[\begin{array}{cc}
\zeta_{11} & 0 \\
0 & \zeta_{22}
\end{array}\right]\left[\begin{array}{cc}
g_{11 t-1}^{2} & 0 \\
0 & g_{22 t-1}^{2}
\end{array}\right] .
\end{aligned}
$$

so that $g_{i i, t} \varepsilon_{i t}=u_{i t}$.

To estimate the simple model structure in (A.1) and (A.2) we need to account for the covariance between $y_{i t}$ and $u_{j t}$ and the identification of structural parameters, and we resolve both estimation issues by working with the reduced-form covariance matrix.

For two assets, the reduced form covariance matrix vech $\mathbf{H}_{t}=\mathbf{A}^{v}$ vecd $\left(\mathbf{G}_{t}\right)$ from equation (12) can be expressed as

$$
\left[\begin{array}{c}
H_{11, t} \\
H_{21, t} \\
H_{22 t}
\end{array}\right]=\left[\begin{array}{cc}
a_{11}^{2} & a_{12}^{2} \\
a_{11} a_{21} & a_{12} a_{22} \\
a_{21}^{2} & a_{22}^{2}
\end{array}\right] \times\left\{\left[\begin{array}{l}
\psi_{1} \\
\psi_{2}
\end{array}\right]+\left[\begin{array}{c}
\lambda_{11} u_{1 t-1}^{2} \\
\lambda_{22} u_{2 t-1}^{2}
\end{array}\right]+\left[\begin{array}{c}
\zeta_{11} g_{11 t-1}^{2} \\
\zeta_{22} g_{22 t-1}^{2}
\end{array}\right]\right\}
$$


From (13) above we can write

$$
\begin{aligned}
\boldsymbol{\kappa}_{t-1} \circ \boldsymbol{\kappa}_{t-1} & =\mathbf{A} \mathbf{u}_{t-1} \circ \mathbf{A} \mathbf{u}_{\mathbf{t}-\mathbf{1}} \\
& =\left[\begin{array}{c}
\left(a_{11} u_{1 t-1}+a_{12} u_{2 t-1}\right)^{2} \\
\left(a_{21} u_{1 t-1}+a_{22} u_{2 t-1}\right)^{2}
\end{array}\right] \\
{\left[\begin{array}{l}
\kappa_{1 t-1}^{2} \\
\kappa_{2 t-1}^{2}
\end{array}\right] } & =\left[\begin{array}{ll}
a_{11}^{2} & a_{12}^{2} \\
a_{21}^{2} & a_{22}^{2}
\end{array}\right]\left[\begin{array}{l}
u_{1 t-1}^{2} \\
u_{2 t-1}^{2}
\end{array}\right] \\
{\left[\begin{array}{ll}
a_{11}^{2} & a_{12}^{2} \\
a_{21}^{2} & a_{22}^{2}
\end{array}\right]^{-1}\left[\begin{array}{l}
\kappa_{1 t-1}^{2} \\
\kappa_{2 t-1}^{2}
\end{array}\right] } & =\left[\begin{array}{ll}
u_{1 t-1}^{2} \\
u_{2 t-1}^{2}
\end{array}\right]
\end{aligned}
$$

using the assumption that the structural shocks are independent so that cross products in $u_{1 t}$ and $u_{2 t}$ can be set to zero. From equation (14)

$$
\begin{aligned}
& \mathbf{h}_{t-1}=\left[\begin{array}{l}
H_{11 t-1} \\
H_{22 t-1}
\end{array}\right]=\left[\begin{array}{ll}
a_{11}^{2} & a_{12}^{2} \\
a_{21}^{2} & a_{22}^{2}
\end{array}\right]\left[\begin{array}{l}
g_{11 t-1}^{2} \\
g_{22 t-1}^{2}
\end{array}\right] \\
& {\left[\begin{array}{ll}
a_{11}^{2} & a_{12}^{2} \\
a_{21}^{2} & a_{22}^{2}
\end{array}\right]^{-1}\left[\begin{array}{l}
H_{11 t-1} \\
H_{22 t-1}
\end{array}\right]=\left[\begin{array}{l}
g_{11 t-1}^{2} \\
g_{22 t-1}^{2}
\end{array}\right] }
\end{aligned}
$$

If we rewrite $\mathbf{H}_{t}$ in vech (.) form and define the requisite transformation of the $\mathbf{A}$ matrix as $\mathbf{A}^{v}$ then

$$
\left[\begin{array}{l}
H_{11, t} \\
H_{21, t} \\
H_{22 t}
\end{array}\right]=\left[\begin{array}{cc}
a_{11}^{2} & a_{12}^{2} \\
a_{11} a_{21} & a_{12} a_{22} \\
a_{21}^{2} & a_{22}^{2}
\end{array}\right]\left\{\begin{array}{r}
{\left[\begin{array}{l}
\psi_{1} \\
\psi_{2}
\end{array}\right]+\left[\begin{array}{cc}
\lambda_{11} & 0 \\
0 & \lambda_{22}
\end{array}\right]\left[\begin{array}{ll}
a_{11}^{2} & a_{12}^{2} \\
a_{21}^{2} & a_{22}^{2}
\end{array}\right]^{-1}\left[\begin{array}{c}
\kappa_{1 t-1}^{2} \\
\kappa_{2 t-1}^{2}
\end{array}\right]} \\
+\left[\begin{array}{cc}
\zeta_{11} & 0 \\
0 & \zeta_{22}
\end{array}\right]\left[\begin{array}{ll}
a_{11}^{2} & a_{12}^{2} \\
a_{21}^{2} & a_{22}^{2}
\end{array}\right]^{-1}\left[\begin{array}{c}
H_{11 t-1} \\
H_{22 t-1}
\end{array}\right]
\end{array}\right\}
$$

\section{A.1. Dynamics}

The proportion of the forecast error variance for return to domestic market one, $y_{1}$, 
that is due to structural shock $\varepsilon_{1}$ is

$$
V D_{1,1 \mid t}=\frac{a_{11}^{2} g_{1, t+1 \mid t}^{2}}{a_{11}^{2} g_{1, t+1 \mid t}^{2}+a_{12}^{2} g_{2, t+1 \mid t}^{2}}
$$

and due to structural shock $\varepsilon_{2}$ is

$$
V D_{1,2 \mid t}=\frac{a_{12}^{2} g_{2, t+1 \mid t}^{2}}{a_{11}^{2} g_{1, t+1 \mid t}^{2}+a_{12}^{2} g_{2, t+1 \mid t}^{2}}
$$

The proportion of portfolio error variance for an equally weighted portfolio includes the impact of diversification, and error sourced in $\varepsilon_{1}$ would be represented by the following expression,

$$
\begin{aligned}
V D_{p, 1} & =\left[g_{1, t+1 \mid t}^{2}\left(a_{11}^{2}+2 a_{21} a_{11}+a_{21}^{2}\right)\right] / \\
& {\left[g_{1, t+1 \mid t}^{2}\left(a_{11}^{2}+2 a_{21} a_{11}+a_{21}^{2}\right)+g_{2, t+1 \mid t}^{2}\left(a_{12}^{2}+2 a_{12} a_{22}+a_{22}^{2}\right)\right] . }
\end{aligned}
$$

Impulse responses in this case are

$$
\begin{aligned}
E_{t}\left[\frac{\partial \mathbf{w}^{\prime} \mathbf{H}_{t+1} \mathbf{w}}{\partial \varepsilon_{1, t}^{2}}\right] & =E_{t}\left\{\partial\left[\begin{array}{cc}
(1 / 2)^{2} & {\left[g_{1, t+1 \mid t}^{2}\left(a_{11}^{2}+2 a_{21} a_{11}+a_{21}^{2}\right)\right.} \\
& \left.+g_{2, t+1 \mid t}^{2}\left(a_{12}^{2}+2 a_{12} a_{22}+a_{22}^{2}\right)\right]
\end{array}\right] / \partial \varepsilon_{1, t}^{2}\right\} \\
& =(1 / 2)^{2}\left(a_{11}^{2}+2 a_{21} a_{11}+a_{21}^{2}\right) E_{t}\left\{\frac{\partial g_{1, t+1 \mid t}^{2}}{\partial \varepsilon_{1, t}^{2}}\right\}
\end{aligned}
$$

which creates a recursion in the structural parameters so that for an initial shock $E_{t}\left(\varepsilon_{1, t}^{2}\right)=$ $\sqrt{E_{t}\left(\varepsilon_{1, t}^{2}\right)}=1$ in period $t$

$$
\begin{aligned}
g_{1, t+1 \mid t}^{2} & =\psi_{1}+\lambda_{1} u_{1, t}^{2}+\zeta_{1} g_{1, t}^{2} \\
E_{t}\left\{\frac{\partial g_{1, t+1 \mid t}^{2}}{\partial \varepsilon_{1, t}^{2}}\right\} & =\lambda_{1} g_{1, t}^{2}
\end{aligned}
$$

and

$$
E_{t}\left[\frac{\partial w^{\prime} \mathbf{H}_{t+1} w}{\partial \varepsilon_{1, t}^{2}}\right]=(1 / 2)^{2}\left(a_{11}^{2}+2 a_{21} a_{11}+a_{21}^{2}\right) \lambda_{1} g_{1, t}^{2}
$$


For the covariance conditional impulse response functions we compute

$$
E_{t}\left[\frac{\partial \mathbf{H}_{t+1}}{\partial \varepsilon_{1, t}^{2}}\right]_{i j}=a_{21} a_{11} \lambda_{1} g_{1, t}^{2}
$$

\section{References}

Akhigbe, A., Madura, J., 2001. Why do contagion effects vary among bank failures? Journal of Banking and Finance 25, 657-680.

Allen, F., Babus, A., 2008. Networks in finance. Working Paper 08-07 Wharton Financial Institutions Centre.

Allen, F., Gale, D., 2000. Financial contagion. Journal of Political Economy 108, 1-33.

Bae, K-H., Karolyi, G.A., Stulz, R.M., 2005. A new approach to measuring financial contagion. Review of Financial Studies 16, 717-763.

Baig, T., Goldfajn, I.,1999. Financial market contagion in the Asian crisis. IMF Staff Papers 46, 167-195.

Baur, D., Schulze, N., 2005. Co-exceedances in financial markets: A quantile regression analysis of contagion. Emerging Markets Review 6, 21-43.

Bekiros, S. D., Georgoutsos, D. A., 2008a. Non-linear dynamics in financial asset returns: The predictive power of the CBOE volatility index. European Journal of Finance 14, 397-408.

Bekiros, S. D., Georgoutsos, D. A., 2008b. The extreme-value dependence of Asia-Pacific equity markets. Journal of Multinational Financial Management 18, 197-208.

Billio, M., Caporin, L., 2005. Multivariate Markov switching dynamic conditional correlation GARCH representations for contagion analysis. Statistical Methods and Applications $14 / 2,145-161$.

Billio, M., Pelizzon, L., 2003. Contagion and interdependence in stock markets: Have they been misdiagnosed? Journal of Economics and Business 55, 405-426.

Brock, W.A., Dechert, A., Lebaron, B., Scheinkman, J.A., 1996. A test for independence based on the correlation dimension. Econometric Reviews 15, 197-235.

Brooks, C., Henry, O.T., 2000. Can portmanteau model nonlinearity tests serve as general model mis-specification diagnostics? Evidence from symmetric and asymmetric GARCH models. Economics Letters 67, 245-51.

Brooks, C., Heravi, S., 1999. The effect of mis-specified GARCH filters on the finite sample distribution of the BDS test. Computational Economics 13, 147-62. 
Brusco, S., Castiglionesi, F., 2007. Liquidity coinsurance, moral hazard and financial contagion. Journal of Finance 62, 2275-2302.

Candelon, B., Piplack, J., Straetmans, S., 2008. On measuring synchronization of bulls and bears: The case of East Asia. Journal of Banking and Finance 32, 1022-1035.

Caporale, G., Cipollini, A., Spagnolo, N., 2005. Testing for contagion: A conditional correlation analysis. Journal of Empirical Finance 12, 476-489.

Castiglionesi, F., 2007. Financial contagion and the role of the central bank. Journal of Banking and Finance 31, 31-101.

Corsetti, G., Pericoli, M., Sbracia, M., 2005. Some contagion, some interdependence: More pitfalls in tests of financial contagion. Journal of International Money and Finance 24, 1177-1199.

Diamond, D.W., Dybvig, P.H., 1983. Bank runs, deposit insurance, and liquidity. Journal of Political Economy 91, 401-419.

Dornbusch, R., Park, Y. C., Claessens, S., 2000. Contagion: Understanding how it spreads. The World Bank Observer 15, 177-197.

Dungey, M., Martin, V.L., 2007. Unravelling financial market linkages during crises. Journal of Applied Econometrics 22, 89-119.

Egloff, D., Lieppold, M., Vanini, P., 2007. A simple model of credit contagion. Journal of Banking and Finance 31, 2475-2492.

Engle, R.F., 1982. Autoregressive conditional heteroscedasticity with estimates of the variance of United Kingdon inflation. Econometrica 50, 987-1007.

Engle, R.F., Ng, V.G., 1993. Measuring and testing the impact of news on volatility. Journal of Finance 48, 1749-1778.

Favero, C., Giavazzi, F., 2002. Is the international propagation of financial shocks nonlinear? Evidence from the ERM. Journal of International Economics 57, 231-46.

Forbes, K., Rigobon, R., 2002. No contagion, only interdependence: Measuring stock market co-movements. Journal of Finance 57, 2223-2261.

Freixas, X., Parigi, B.M., Rochet, J-C., 2000. Systemic risk, interbank relations, and liquidity provision by the central bank. Journal of Money, Credit and Banking 32, 611638.

Furfine, C., 2003. Interbank exposure: Quantifying the risk of contagion. Journal of Money, Credit and Banking 35, 111-128.

Gallant, A.R., Rossi, P.E., Tauchen, G., 1993. Nonlinear dynamic structures. Econometrica $61,871-907$.

Giesecke, K., Weber, S., 2004. Cyclical correlations, credit contagion and portfolio loss. Journal of Banking and Finance 28, 3009-3036.

Hasman, A., Samartín, M., 2008. Information acquisition and financial contagion. Journal of Banking and Finance 32, 2136-2147. 
Hinich, M.J., 1982. Testing for Gaussianity and linearity of a stationary time series. Journal of Times Series Analysis 3, 169-176.

Kaminsky, G., Reinhart, C., 2002. Financial markets under stress. Journal of Development Economics 69, 451-470.

Kodres, L., Pritsker, M., 2002. A rational expectations model of financial contagion. Journal of Finance 57, 769-799.

Kyrtsou, C., Labys, W., 2006. Evidence for chaotic dependence between US inflation and commodity prices. Journal of Macroeconomics 28, 256-266.

Kyrtsou, C., Serletis, A., 2006. Univariate tests for nonlinear structure. Journal of Macroeconomics 28, 154-168.

Lin, W-L., 1997. Impulse response function for conditional volatility in GARCH Models. Journal of Business and Economic Statistics 15, 15-25.

Markwat, T., Kole, E., van Dijk, D., 2009. Contagion as a domino effect in global stock markets. Journal of Banking and Finance 33, 1996-2012.

Pesaran, H., Pick, A., 2007. Econometric issues in the analysis of contagion. Journal of Economic Dynamics and Control 31, 1245-1277.

Pavlova, A., Rigobon, R., 2007. The role of portfolio constraints in the international propagation of shocks. Review of Economic Studies, forthcoming.

Rigobon, R., 2003. On the measurement of the international propagation of shocks: Is the transmission stable? Journal of International Economics 61, 261-283.

Rigobon, R., Sack, B., 2004. Impact of monetary policy on asset prices. Journal of Monetary Economics 51, 1553-1575.

Rothenberg, T., 1971. Identification in parametric models. Econometrica 39, 577-591.

Tsay, R. S., 1986. Nonlinearity tests for time series. Biometrika 73, 461-466.

Yang, J., Zhou, Y., Wang, Z., 2009. The stock-bond correlation and macroeconomic conditions: One and a half centuries of evidence. Journal of Banking and Finance, 33, 670-680.

Yuan, K., 2005. Asymmetric price movements and borrowing constraints: A rational expectations equilibrium model of crises, contagion, and confusion. Journal of Finance $60,379-411$. 
Figure 1: Time Series of Filtered Daily Returns to Asian Equity Price Indices, January 1992 to January 2007.
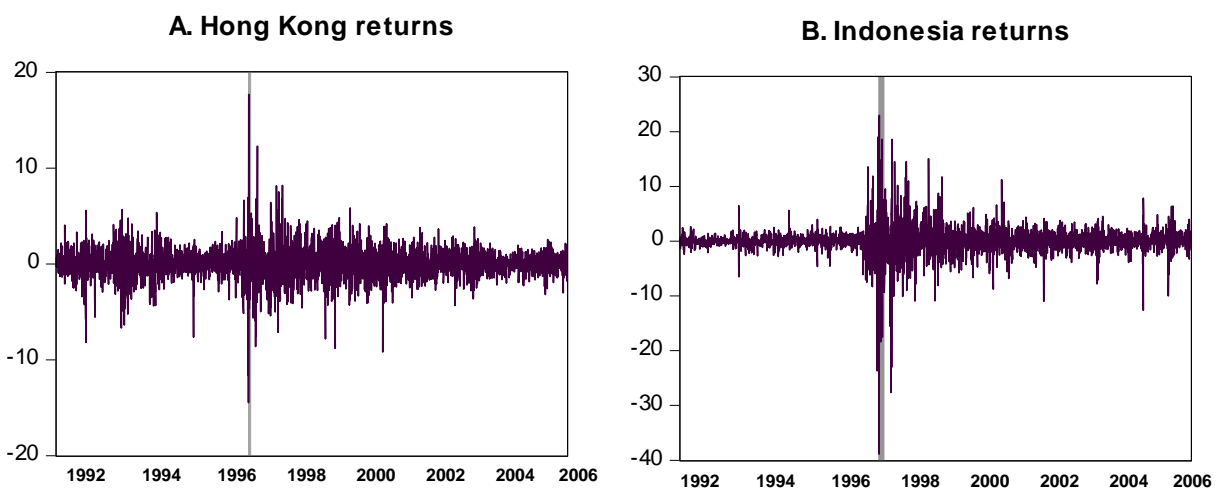

C. Korea returns

D. Thailand returns
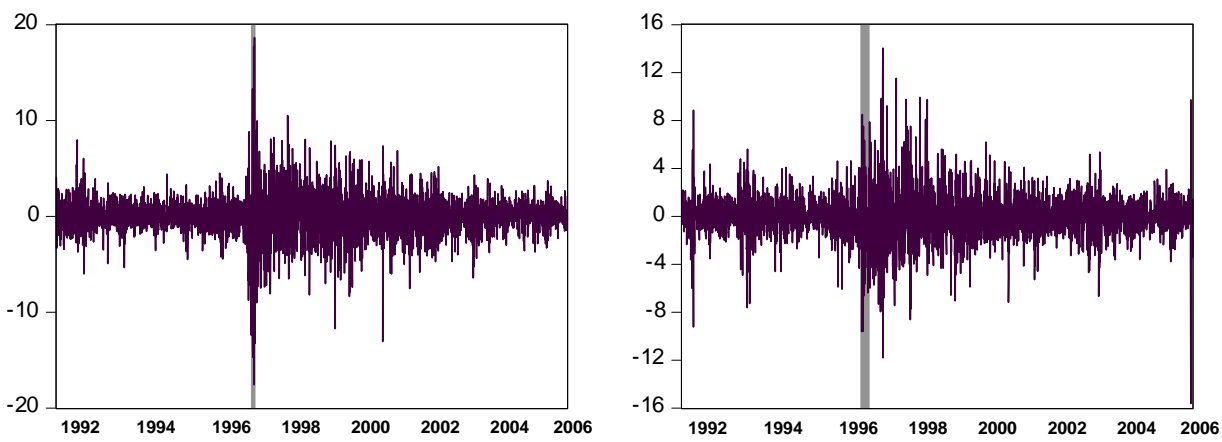

Note: Each series is the residuals from a VAR(1). Grey bars indicate the period designated as crisis period in each country. Data sources are described in Table 1. 
Figure 2: Standardized residuals from fitted SGARCH model, January 1992 to January 2007.
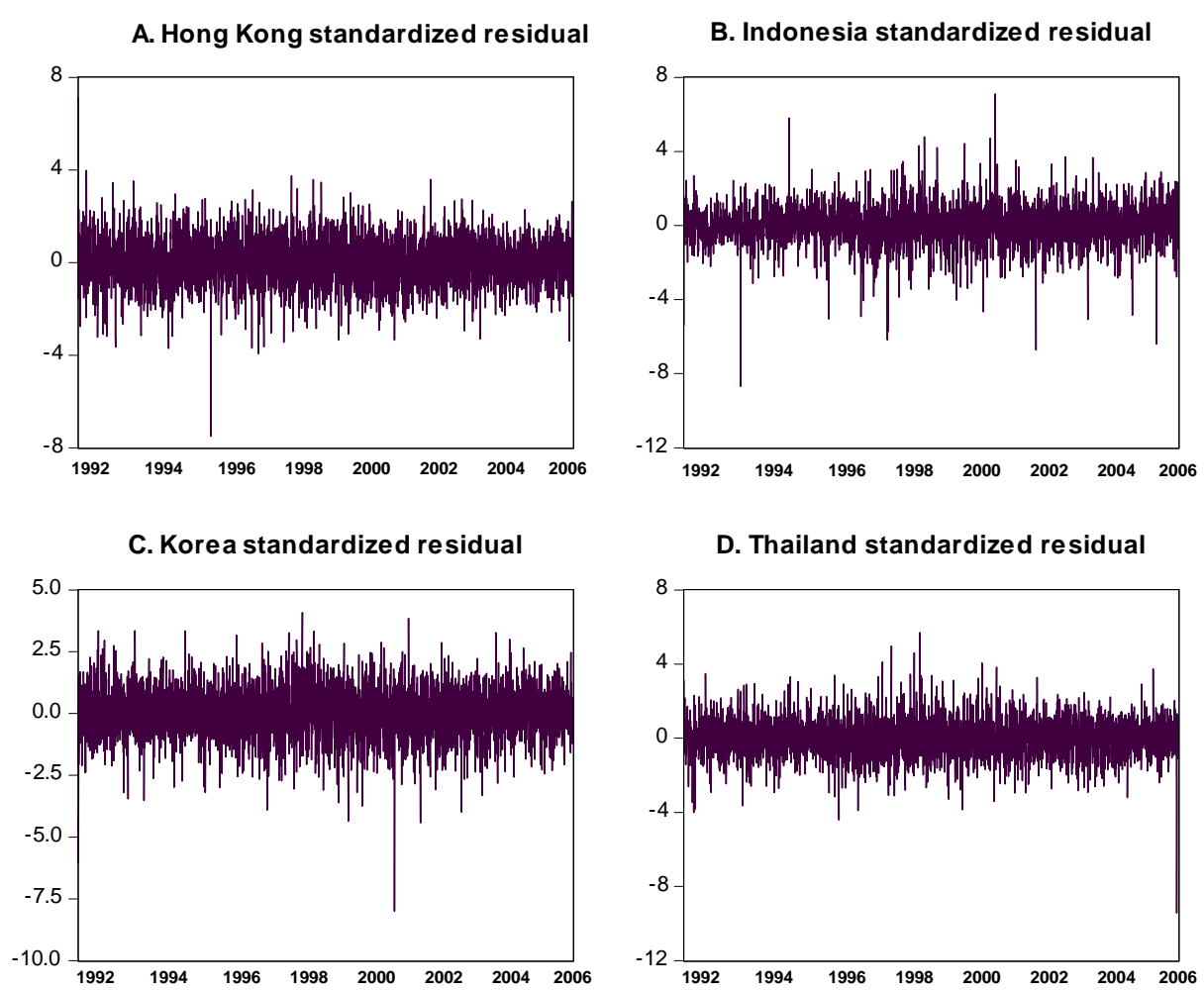

Note: Each series is the structural residual from the fitted SGARCH model standardized by the fitted conditional structural standard deviation for the relevant market and time period 
Figure 3: Impulse Response Functions of Equally Weighted Portfolio Variance to a Standard Deviation Shock for Periods of Tranquility and Contagion

Tranquil Period

\section{A. Hong Kong sourced shock}

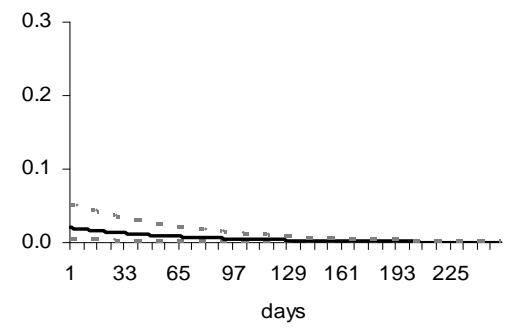

\section{Contagion}

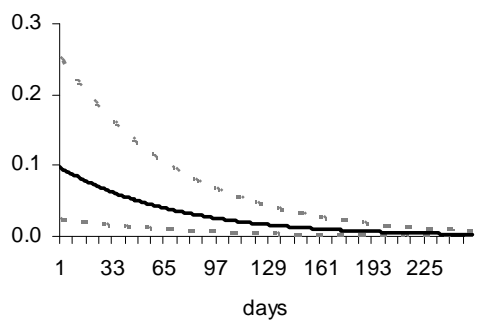

B. Indonesian sourced shock
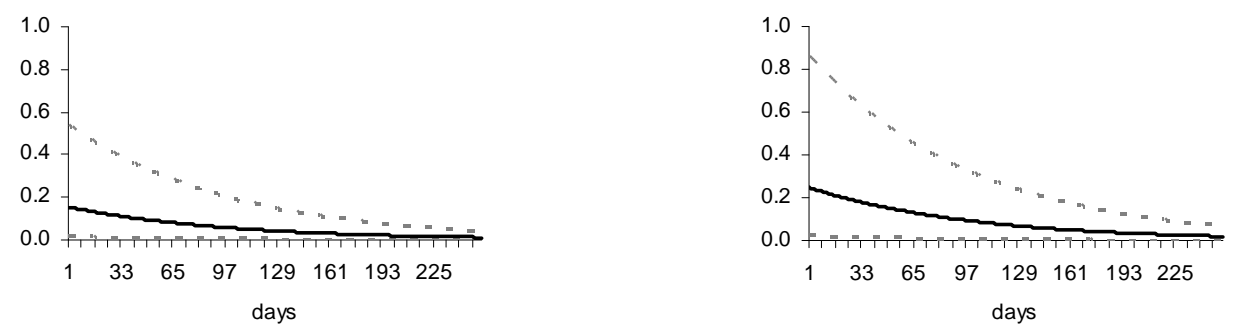

C. Korean sourced shock
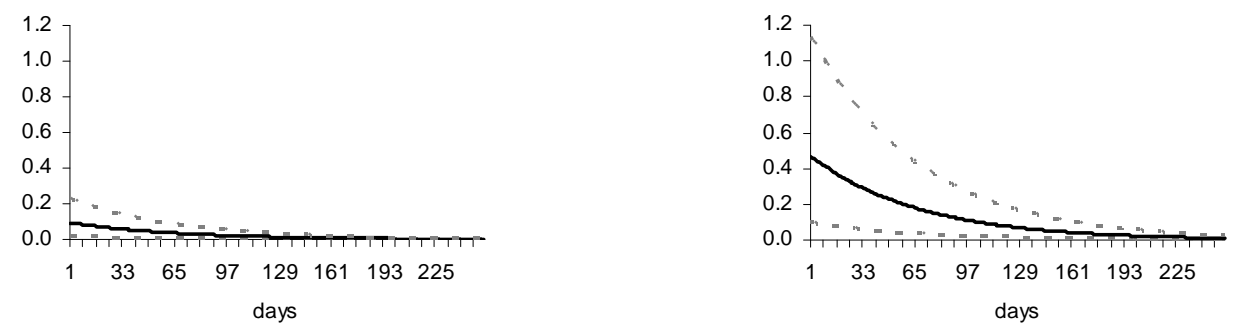

D. Thai sourced shock
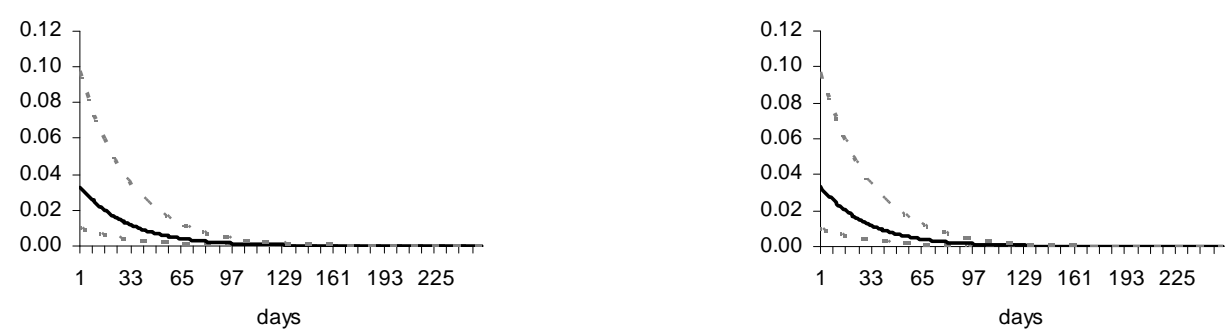

Note: Vertical axes show the absolute increase in the daily variance of an equally-weighted portfolio of the equity indices n-days after a one standard deviation structural shock from each equity market. Impulse response functions are calculated conditioning on volatility at every time $=t$ in the sample. The dashed lines represent the 5th and 95th quantiles of the empirical distribution of the conditional impulse responses and the solid line represents the median. 
Figure 4: Impulse Response Functions of Market Covariances to a Standard Deviation Shock from Hong Kong for Periods of Tranquility and Contagion

Tranquil Period

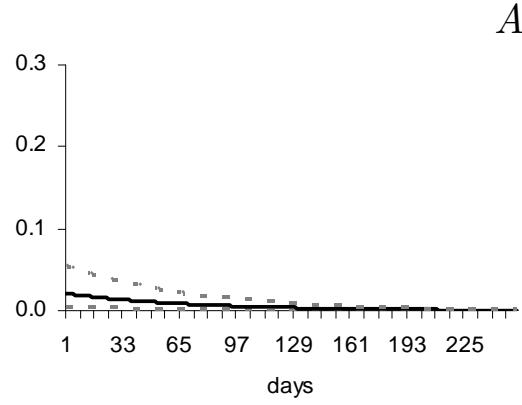

\section{Contagion}

A. Hong Kong-Indonesia

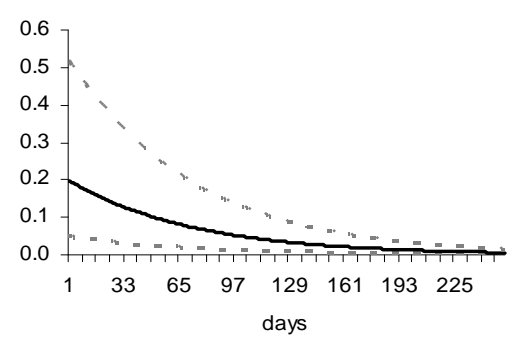

B. Hong Kong-Korea
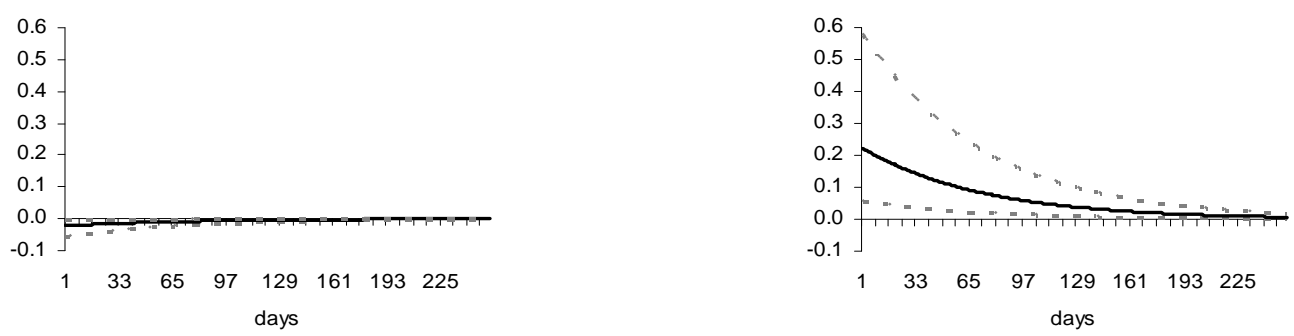

C. Hong Kong-Thailand
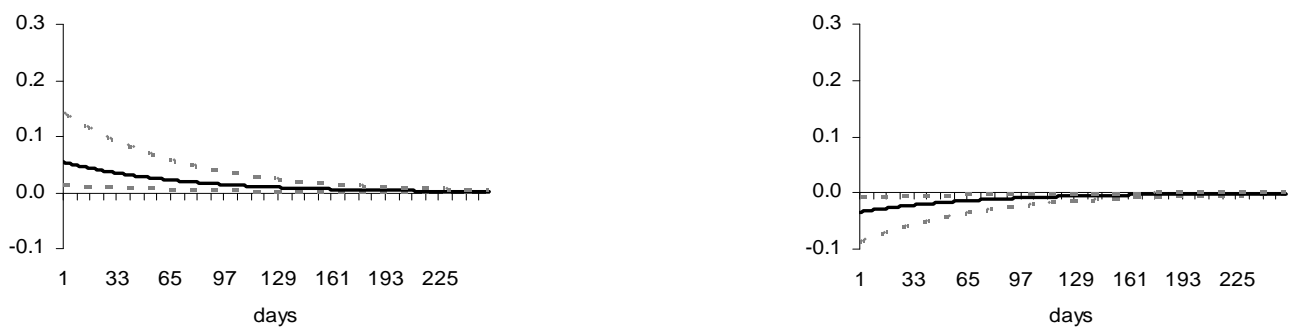

D. Indonesia-Korea

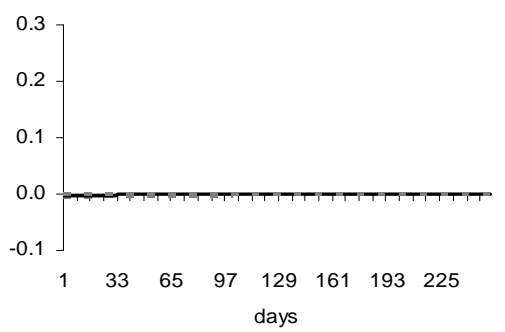

Note: Vertical axes show the absolute increase in the daily covariance between selected equity indices n-days after a one standard deviation structural shock from Hong Kong equity market. Impulse response functions are calculated conditioning on volatility at every time $=t$ in the sample. The dashed lines represent the 5th and 95th quantiles of the empirical distribution of the conditional impulse responses and the solid line represents the median. 
Table 1:

Descriptive Statistics for Equity Returns: Tranquil Period and Crisis Periods

\begin{tabular}{|c|c|c|c|c|}
\hline & $\begin{array}{c}\text { Hong Kong } \\
\text { (HK) }\end{array}$ & $\begin{array}{l}\text { Indonesia } \\
\text { (IN) }\end{array}$ & $\begin{array}{c}\text { Korea } \\
(\mathrm{KO})\end{array}$ & $\begin{array}{c}\text { Thailand } \\
(\mathrm{TH})\end{array}$ \\
\hline \multicolumn{5}{|c|}{ Total Period: 2 January 1992-9 January 2007} \\
\hline Mean & 0.000 & 0.000 & 0.000 & 0.000 \\
\hline Std dev. & 1.606 & 2.456 & 2.169 & 1.885 \\
\hline Skew & 0.016 & -1.436 & -0.127 & 0.168 \\
\hline Kurt & 13.354 & 40.469 & 12.977 & 9.500 \\
\hline J-B p-val & 0.000 & 0.000 & 0.000 & 0.000 \\
\hline \multicolumn{5}{|c|}{ Thai crisis: 10 June 1997 - 29 August 1997} \\
\hline Mean & -0.061 & -0.642 & -0.053 & -0.500 \\
\hline Std dev. & 1.662 & 2.487 & 1.062 & 3.832 \\
\hline Skew & -0.390 & -0.857 & -0.102 & 0.079 \\
\hline Kurt & 4.942 & 4.128 & 2.751 & 3.190 \\
\hline J-B p-val & 0.001 & 0.007 & 0.884 & 0.930 \\
\hline \multicolumn{5}{|c|}{ Hong Kong crisis: 27 October $1997-17$ November $199^{7}$} \\
\hline Mean & -0.353 & -0.168 & -0936 & -0.450 \\
\hline Std dev. & 6.767 & 5.155 & 4.936 & 3.776 \\
\hline Skew & 0.700 & 1.010 & 0.210 & 0.271 \\
\hline Kurt & 5.046 & 3.631 & 2.325 & 2.204 \\
\hline J-B p-val & 0.129 & 0.226 & 0.810 & 0.734 \\
\hline
\end{tabular}

Korean crisis: 25 November 1997 - 31 December 1997

\begin{tabular}{|c|c|c|c|c|}
\hline Mean & 0.137 & -0.723 & -1.191 & -1.002 \\
\hline Std dev. & 2.435 & 7.671 & 10.916 & 2.942 \\
\hline Skew & -0.485 & -0.331 & 0.333 & 0.288 \\
\hline Kurt & 2.959 & 5.737 & 2.010 & 2.969 \\
\hline J-B p-val & 0.612 & 0.016 & 0.477 & 0.841 \\
\hline \multicolumn{5}{|c|}{ Indonesian crisis: 5 January 1998 to 27 February 1998} \\
\hline Mean & -0.019 & -1.599 & 0.496 & 1.166 \\
\hline Std dev. & 3.982 & 11.600 & 5.193 & 5.310 \\
\hline Skew & 0.496 & -0.527 & -0.461 & -0.034 \\
\hline Kurt & 4.360 & 4.538 & 2.976 & 3.4168 \\
\hline J-B p-val & 0.112 & 0.069 & 0.520 & 0.872 \\
\hline
\end{tabular}

Note: Returns are computed as percentage log changes in the price indices for Hong Kong

(Hang Seng HNGKNGI), Indonesia (Jakarta Composite JAKCOMP), Korea (Korea Composite KORCOMP) and Thailand (Bangkok SET BNGKSET) using daily series from Datastream, translated to US dollars before returns are computed. Sample runs from 2 January 1992 to 9 January 2007 but observations where there is a zero return from any series are removed before de-meaning, leaving 3607 days. Returns are filtered using a $\operatorname{VAR}(1)$ in the returns and the contemporaneous daily 3 -month US Treasury Bill secondary market mid-rate 
Table 2:

Tests for linearity and Gaussianity in returns, VAR residuals and standardized SGARCH residuals.

\begin{tabular}{lcccc}
\hline \hline & \multicolumn{4}{c}{$p-$ values } \\
& $\begin{array}{c}\text { Tsay (1986) } \\
8 \text { lags }\end{array}$ & $\begin{array}{c}\text { Engle (1982) } \\
8 \text { lags }\end{array}$ & $\begin{array}{c}\text { Hinich }(1982) \\
\text { 210 lattice points }\end{array}$ \\
\hline$H_{0}$ & Linarity in mean & no ARCH & Linearity & Gaussianity \\
\hline Returns, $r_{i t}$ & & & & \\
Hong Kong & 0.000 & 0.000 & 0.000 & 0.000 \\
Indonesia & 0.000 & 0.000 & 0.000 & 0.000 \\
\hline Korea & 0.000 & 0.000 & 0.000 & 0.000 \\
Thailand & 0.000 & 0.000 & 0.000 & 0.000 \\
& & & & \\
\hline VAR residuals, $y_{i t}$ & & & & \\
Hong Kong & 0.000 & 0.000 & 0.000 & 0.000 \\
Indonesia & 0.000 & 0.000 & 0.000 & 0.000 \\
Korea & 0.000 & 0.000 & 0.000 & 0.000 \\
Thailand & 0.000 & 0.000 & 0.000 & 0.000 \\
& & & & \\
\hline Standardized residuals, $\varepsilon_{i t}$ & & & & \\
Hong Kong & 0.544 & 0.789 & 0.279 & 0.002 \\
Indonesia & 0.050 & 0.150 & 0.939 & 0.006 \\
Korea & 0.020 & 0.780 & 0.005 & 0.000 \\
Thailand & 0.654 & 0.086 & 0.093 & 0.000 \\
\hline
\end{tabular}

Note: Table reports p-values for Tsay (1986) test for linearity in means, Engle (1982) test for ARCH effects, and Hinich (1982) bispectrum test for linearity and Gaussianity, for returns (log changes in US dollar values of equity price indexes), residuals from VAR(1) filtering of the returns series including contemporaneous values of the 3 month US T-bill, and the standardized structural residuals from the SGARCH model fitted to the VAR residuals. For computation of test statistics see Kyrtsou and Serletis (2006). 
Table 3:

BDS tests for departures from randomness in returns, VAR residuals and standardized SGARCH residuals.

\begin{tabular}{|c|c|c|c|c|c|c|c|c|c|c|c|c|}
\hline \multirow[b]{3}{*}{ distance, $\varepsilon$} & \multicolumn{12}{|c|}{$p$-values } \\
\hline & \multicolumn{4}{|c|}{ Returns, $r_{i t}$} & \multicolumn{4}{|c|}{ VAR residuals, $y_{i t}$} & \multicolumn{4}{|c|}{ Standardized residuals, $\varepsilon_{i t}$} \\
\hline & $0.5 \sigma$ & $\sigma$ & $1.5 \sigma$ & $2 \sigma$ & $0.5 \sigma$ & $\sigma$ & $1.5 \sigma$ & $2 \sigma$ & $0.5 \sigma$ & $\sigma$ & $1.5 \sigma$ & $2 \sigma$ \\
\hline \multicolumn{13}{|l|}{ Hong Kong } \\
\hline$m=2$ & 0 & 0 & 0 & 0 & 0 & 0 & 0 & 0 & 0.583 & 0.607 & 0.909 & 0.494 \\
\hline$m=3$ & 0 & 0 & 0 & 0 & 0 & 0 & 0 & 0 & 0.611 & 0.734 & 0.958 & 0.513 \\
\hline$m=4$ & 0 & 0 & 0 & 0 & 0 & 0 & 0 & 0 & 0.394 & 0.495 & 0.721 & 0.673 \\
\hline$m=5$ & 0 & 0 & 0 & 0 & 0 & 0 & 0 & 0 & 0.266 & 0.292 & 0.398 & 0.959 \\
\hline$m=6$ & 0 & 0 & 0 & 0 & 0 & 0 & 0 & 0 & 0.105 & 0.144 & 0.212 & 0.652 \\
\hline \multicolumn{13}{|l|}{ Indonesia } \\
\hline$m=2$ & 0 & 0 & 0 & 0 & 0 & 0 & 0 & 0 & 0 & 0 & 0.0002 & 0.006 \\
\hline$m=3$ & 0 & 0 & 0 & 0 & 0 & 0 & 0 & 0 & 0 & 0 & 0 & 0.002 \\
\hline$m=4$ & 0 & 0 & 0 & 0 & 0 & 0 & 0 & 0 & 0 & 0 & 0.0004 & 0.005 \\
\hline$m=5$ & 0 & 0 & 0 & 0 & 0 & 0 & 0 & 0 & 0.001 & 0.001 & 0.004 & 0.025 \\
\hline$m=6$ & 0 & 0 & 0 & 0 & 0 & 0 & 0 & 0 & 0.003 & 0.003 & 0.013 & 0.050 \\
\hline \multicolumn{13}{|l|}{ Korea } \\
\hline$m=2$ & 0 & 0 & 0 & 0 & 0 & 0 & 0 & 0 & 0.101 & 0.101 & 0.106 & 0.187 \\
\hline$m=3$ & 0 & 0 & 0 & 0 & 0 & 0 & 0 & 0 & 0.106 & 0.109 & 0.137 & 0.378 \\
\hline$m=4$ & 0 & 0 & 0 & 0 & 0 & 0 & 0 & 0 & 0.128 & 0.159 & 0.283 & 0.712 \\
\hline$m=5$ & 0 & 0 & 0 & 0 & 0 & 0 & 0 & 0 & 0.147 & 0.249 & 0.401 & 0.796 \\
\hline$m=6$ & 0 & 0 & 0 & 0 & 0 & 0 & 0 & 0 & 0.150 & 0.383 & 0.552 & 0.916 \\
\hline \multicolumn{13}{|l|}{ Thailand } \\
\hline$m=2$ & 0 & 0 & 0 & 0 & 0 & 0 & 0 & 0 & 0.031 & 0.135 & 0.575 & 0.980 \\
\hline$m=3$ & 0 & 0 & 0 & 0 & 0 & 0 & 0 & 0 & 0.131 & 0.350 & 0.908 & 0.599 \\
\hline$m=4$ & 0 & 0 & 0 & 0 & 0 & 0 & 0 & 0 & 0.319 & 0.596 & 0.981 & 0.603 \\
\hline$m=5$ & 0 & 0 & 0 & 0 & 0 & 0 & 0 & 0 & 0.418 & 0.664 & 0.982 & 0.710 \\
\hline$m=6$ & 0 & 0 & 0 & 0 & 0 & 0 & 0 & 0 & 0.251 & 0.495 & 0.751 & 0.952 \\
\hline
\end{tabular}

Note: Table reports p-values for BDS (Brock et al. 1996) tests for pure randomness in returns (log changes in US dollar values of equity price indexes), residuals from VAR(1) filtering of the returns series including contemporaneous values of the 3 month US T-bill, and the standardized structural residuals from the SGARCH model fitted to the VAR residuals. The parameter $\varepsilon$ sets the benchmark for comparing distances between consecutive pairs of points in the test sample and the embedding dimension, $m$, sets the number of pairs in each comparison set. See Brock et al. (1996) for details. 
Table 4:

Parameter Estimation Results: Tranquil Periods

\begin{tabular}{|c|c|c|c|c|c|}
\hline & & \multicolumn{4}{|c|}{ TO market $i\left(y_{i}\right)$} \\
\hline & & $\begin{array}{c}\text { Hong Kong } \\
(\mathrm{HK})\end{array}$ & $\begin{array}{l}\text { Indonesia } \\
\text { (IN) }\end{array}$ & $\begin{array}{c}\text { Korea } \\
(\mathrm{KO})\end{array}$ & $\begin{array}{c}\text { Thailand } \\
\text { (TH) }\end{array}$ \\
\hline FROM market $j,\left(y_{j}\right)$ & & & & & \\
\hline Hong Kong & $b_{i, H K}$ & & $\begin{array}{c}0.103 \\
(0.003)\end{array}$ & $\begin{array}{l}-0.125 \\
(0.050)\end{array}$ & $\begin{array}{c}0.263 \\
(0.000)\end{array}$ \\
\hline Indonesia & $b_{i, I N}$ & $\begin{array}{c}0.086 \\
(0.001)\end{array}$ & & $\begin{array}{c}0.148 \\
(0.006)\end{array}$ & $\begin{array}{c}0.152 \\
(0.000)\end{array}$ \\
\hline Korea & $b_{i, K O}$ & $\begin{array}{c}0.296 \\
(0.000)\end{array}$ & $\begin{array}{c}0.009 \\
(0.812)\end{array}$ & & $\begin{array}{c}0.098 \\
(0.031)\end{array}$ \\
\hline Thailand & $b_{i, T H}$ & $\begin{array}{c}0.032 \\
(0.533)\end{array}$ & $\begin{array}{c}0.034 \\
(0.430)\end{array}$ & $\begin{array}{c}0.024 \\
(0.642)\end{array}$ & \\
\hline
\end{tabular}

Note: Parameter estimates for the model $\mathbf{B}^{*} \mathbf{Y}_{t}=\mathbf{u}_{t}$, where $\left(\mathbf{B}+\mathbf{B}_{\mathbf{c}} \mathbf{D}_{\mathbf{t}}+\mathbf{D}_{\mathbf{t}} \mathbf{B}_{\mathbf{s}}\right) \mathbf{Y}_{t}=\mathbf{B}^{*} \mathbf{Y}$ with $\mathbf{B}_{\mathbf{c}} \mathbf{D}_{\mathbf{t}}+\mathbf{D}_{\mathbf{t}} \mathbf{B}_{\mathbf{s}}$ representing the linkages present in crisis periods. Estimation is by QML over daily filtered returns to equity market indices, sampling 6 January 1992 to 9 January 2007.

P-values are in brackets. 
Table 5:

Parameter Estimation Results: Hypersensitivity During Crises in market $i$

\begin{tabular}{lccccc}
\hline \hline \multicolumn{5}{c}{ TO market $i\left(y_{i}\right)$} & when $D_{i t}=1$ \\
& & Hong Kong & Indonesia & Korea & Thailand \\
& $(\mathrm{HK})$ & $(\mathrm{IN})$ & $(\mathrm{KO})$ & $(\mathrm{TH})$ \\
\hline FROM market $j,\left(y_{j}\right)$ & & & & & \\
Hong Kong & $b_{s, i, H K}$ & & -2.050 & -1.981 & 0.424 \\
& & & $(0.191)$ & $(0.246)$ & $(0.451)$ \\
Indonesia & $b_{s, i, I N}$ & 0.814 & & -0.753 & 0.238 \\
& & $(0.000)$ & & $(0.031)$ & $(0.168)$ \\
Korea & $b_{s, i, K O}$ & -0.751 & -0.636 & & -0.687 \\
& & $(0.013)$ & $(0.505)$ & & $(0.415)$ \\
Thailand & $b_{s, i, T H}$ & 0.475 & 1.346 & 0.927 & \\
& & $(0.234)$ & $(0.341)$ & $(0.467)$ & \\
\hline
\end{tabular}

Note: Parameter estimates for the model $\mathbf{B}^{*} \mathbf{Y}_{t}=\mathbf{u}_{t}$, where $\left(\mathbf{B}+\mathbf{B}_{\mathbf{c}} \mathbf{D}_{\mathbf{t}}+\mathbf{D}_{\mathbf{t}} \mathbf{B}_{\mathbf{s}}\right) \mathbf{Y}_{t}=\mathbf{B}^{*} \mathbf{Y}$ with $\mathbf{B}_{\mathbf{c}} \mathbf{D}_{\mathbf{t}}+\mathbf{D}_{\mathbf{t}} \mathbf{B}_{\mathbf{s}}$ representing the linkages present in crisis periods. Each period of crisis is identified using an indicator variable $D_{i, t}$ which is one during the crisis in home country $i$ and zero otherwise. Hypersensitivity (indicated by subscript $s$ ) is given by the parameter $b_{s, i j}$ in each equation, operating when $D_{i t}=1$, measuring the additional impact of foreign shocks during a domestic crisis. The relevance of each instance of hypersensitivity is tested by the significance of the parameters $b_{s, i j}$. Estimation is by QML over daily filtered returns to equity market indices, sampling 6 January 1992 to 9 January 2007. P-values are in brackets. 
Table 6:

Parameter Estimation Results: Contagion During Crises in market $j$.

\begin{tabular}{lccccc}
\hline \hline & & \multicolumn{3}{c}{ TO market $i\left(y_{i}\right)$} \\
& & $\begin{array}{c}\text { Hong Kong } \\
\text { Indonesia } \\
\text { (HK) }\end{array}$ & $\begin{array}{c}\text { Korea } \\
(\mathrm{INO})\end{array}$ & $\begin{array}{c}\text { Thailand } \\
(\mathrm{TH})\end{array}$ \\
\hline $\begin{array}{l}\text { FROM market } j,\left(y_{j}\right) \text { when } D_{j t}=1 \\
\text { Hong Kong }\end{array}$ & $b_{c, i, H K}$ & & 0.180 & 0.665 & -0.504 \\
& & & $(0.263)$ & $(0.003)$ & $(0.021)$ \\
Indonesia & $b_{c, i, I N}$ & 0.128 & & 0.145 & -0.127 \\
Korea & & $(0.266)$ & & $(0.488)$ & $(0.569)$ \\
& $b_{c, i, K O}$ & -0.153 & 0.727 & & -0.007 \\
Thailand & & $(0.276)$ & $(0.001)$ & & $(0.917)$ \\
& $b_{c, i, T H}$ & -0.175 & -0.051 & -0.092 & \\
\hline
\end{tabular}

Note: Parameter estimates for the model $\mathbf{B}^{*} \mathbf{Y}_{t}=\mathbf{u}_{t}$, where $\left(\mathbf{B}+\mathbf{B}_{\mathbf{c}} \mathbf{D}_{\mathbf{t}}+\mathbf{D}_{\mathbf{t}} \mathbf{B}_{\mathbf{s}}\right) \mathbf{Y}_{t}=\mathbf{B}^{*} \mathbf{Y}$ with $\mathbf{B}_{\mathbf{c}} \mathbf{D}_{\mathbf{t}}+\mathbf{D}_{\mathbf{t}} \mathbf{B}_{\mathbf{s}}$ representing the linkages present in crisis periods. Each period of crisis is identified using an indicator variable $D_{i, t}$ which is one during the crisis in home country $i$ and zero otherwise. Contagion (indicated by subscript $c$ ) is modelled as the additional impact on asset markets in home country $i$ during a crisis in foreign country $j$, given by the parameter $b_{s, i j}$ in each equation, operating when $D_{j t}=1$. The relevance of each instance of contagion is tested by the significance of the parameters $b_{c, i j}$. Estimation is by QML over daily filtered returns to equity market indices, sampling 6 January 1992 to 9 January 2007. P-values are in brackets. 
Table 7:

GARCH parameter estimates

\begin{tabular}{|c|c|c|c|c|c|}
\hline & $i$ & Hong Kong & $\begin{array}{r}\text { Structural } \\
\text { Indonesia }\end{array}$ & $\begin{array}{l}\text { Shocks } \\
\text { Korea }\end{array}$ & Thailand \\
\hline Constant & $\psi_{i}$ & $\begin{array}{c}0.029 \\
(0.036)\end{array}$ & $\begin{array}{c}0.070 \\
(0.020)\end{array}$ & $\begin{array}{c}0.079 \\
(0.002)\end{array}$ & $\begin{array}{c}0.115 \\
(0.037)\end{array}$ \\
\hline $\mathrm{ARCH}$ & $\lambda_{i}$ & $\begin{array}{c}0.089 \\
(0.000)\end{array}$ & $\begin{array}{c}0.181 \\
(0.000)\end{array}$ & $\begin{array}{c}0.126 \\
(0.000)\end{array}$ & $\begin{array}{c}0.171 \\
(0.003)\end{array}$ \\
\hline GARCH & $\zeta_{i}$ & $\begin{array}{c}0.897 \\
(0.000)\end{array}$ & $\begin{array}{c}0.809 \\
(0.000)\end{array}$ & $\begin{array}{c}0.859 \\
(0.000)\end{array}$ & $\begin{array}{c}0.797 \\
(0.000)\end{array}$ \\
\hline
\end{tabular}

Note: Parameter estimates for the conditional covariance matrix of the structural shocks, $G_{t}=\operatorname{diag}\left[\psi+\lambda\left(\mathbf{u}_{t-1} \circ \mathbf{u}_{t-1}\right)\right]+\zeta G_{t-1}$, where $\psi$ is a $4 \times 1$ vector of constants, $\lambda$ is a $4 \times 4$ diagonal matrix of ARCH coefficients and $\zeta$ is a $4 \times 4$ diagonal matrix of GARCH coefficients.

Estimation is by QML over daily filtered returns to equity market indices, sampling 6 January 1992 to 9 January 2007. P-values are in brackets. 
Table 8:

Mean Conditional Forecast Error Variance Decomposition (One Step Ahead)

\begin{tabular}{|c|c|c|c|c|c|}
\hline$\varepsilon_{i}$ & Hong Kong & Indonesia & Korea & Thailand & portfolio \\
\hline & & & Tranquil & & \\
\hline \multirow[t]{2}{*}{ Hong Kong } & 80.38 & 1.10 & 0.81 & 5.04 & 15.56 \\
\hline & {$[61.89-95.19]$} & {$[0.12-3.42]$} & {$[0.20-2.39]$} & {$[1.56-11.82]$} & {$[4.81-38.40]$} \\
\hline \multirow[t]{2}{*}{ Indonesia } & 3.06 & 98.74 & 1.99 & 5.33 & 30.88 \\
\hline & {$[0.44-9.16]$} & 96.30-99.83] & [0.39-5.53] & {$[0.91-15.27]$} & [10.79-63.63] \\
\hline \multirow[t]{2}{*}{ Korea } & 16.59 & 0.16 & 97.21 & 4.76 & 39.47 \\
\hline & {$[4.06-33.57]$} & {$[0.03-0.42]$} & [93.06-99.23] & {$[1.20-11.59]$} & [16.11-64.30] \\
\hline \multirow[t]{3}{*}{ Thailand } & 0.00 & 0.00 & 0.00 & 84.87 & 14.09 \\
\hline & {$[0.00-0.00]$} & {$[0.00-0.00]$} & {$[0.00-0.00]$} & [69.44-94.98] & {$[4.32-29.80]$} \\
\hline & \multicolumn{5}{|c|}{ Hypersensitivity } \\
\hline \multirow[t]{2}{*}{ Hong Kong } & 31.26 & 1.32 & 1.83 & 6.25 & 21.29 \\
\hline & [7.71-65.00] & [0.15-64.09] & {$[0.42-5.63]$} & [1.85-14.93] & {$[4.72-48.28]$} \\
\hline \multirow[t]{2}{*}{ Indonesia } & 55.99 & 98.23 & 32.44 & 20.56 & 60.36 \\
\hline & {$[24.38-86.43]$} & {$[95.10-99.74]$} & [11.17-65.11] & {$[4.72-50.79]$} & [29.49-88.91] \\
\hline \multirow[t]{2}{*}{ Korea } & 12.75 & 0.45 & 65.73 & 0.27 & 4.06 \\
\hline & [3.60-26.13] & {$[0.08-1.17]$} & [33.99-87.28] & {$[0.07-0.66]$} & {$[1.05-9.22]$} \\
\hline \multirow[t]{3}{*}{ Thailand } & 0.00 & 0.00 & 0.00 & 72.91 & 14.29 \\
\hline & {$[0.00-0.00]$} & {$[0.00-0.00]$} & {$[0.00-0.00]$} & [44.37-91.19] & {$[3.50-31.46]$} \\
\hline & & & Contagion & & \\
\hline \multirow[t]{2}{*}{ Hong Kong } & 70.91 & 11.75 & 15.29 & 1.19 & 22.01 \\
\hline & [48.07-91.80] & [02.79-32.02] & {$[4.75-37.83]$} & {$[0.35-12.88]$} & [7.80-50.37] \\
\hline \multirow[t]{2}{*}{ Indonesia } & 3.28 & 41.92 & 3.23 & 4.06 & 16.34 \\
\hline & [0.51-9.65] & [17.21-75.20] & [0.68-9.05] & {$[0.67-11.67]$} & [4.44-40.63] \\
\hline \multirow[t]{2}{*}{ Korea } & 25.81 & 46.33 & 81.49 & 5.56 & 57.17 \\
\hline & {$[47.22-47.98]$} & [19.60-71.35] & [58.57-93.48] & [1.35-13.57] & [289.63-79.18] \\
\hline \multirow[t]{2}{*}{ Thailand } & 0.00 & 0.00 & 0.00 & 89.19 & 4.47 \\
\hline & {$[0.00-0.00]$} & {$[0.00-0.00]$} & [0.00-0.00] & [76.38-96.88] & [1.30-9.73] \\
\hline
\end{tabular}

Note: Conditional one-step ahead error variance decompositions, computed for individual assets and an equally-weighted portfolio of market indices. Rows show the mean of empirical histogram of the conditional variance decompositions, conditioning on each standard deviation $g_{i i, t}$ in the sample, and figures in square brackets are the 5th and 95th quantiles. 